(C) 2015, Elsevier. Licensed under the Creative Commons Attribution-NonCommercial-NoDerivatives 4.0 International

http://creativecommons.org/licenses/by-nc-nd/4.0/

Elsevier Editorial System(tm) for Computers \& Chemical Engineering Manuscript Draft

Manuscript Number: CACE-D-14-00647R1

Title: Solid oxide fuel cell reactor analysis and optimisation through a novel multi-scale modelling strategy

Article Type: Full Length Paper

Section/Category: Modeling, numerical analysis and simulation

Keywords: Solid Oxide Fuel Cell, Aspen Plus, Multi-Scale, Optimisation, Modelling

Corresponding Author: Professor Moses Oludayo Tade, PhD

Corresponding Author's Institution: Curtin Univ. of Technology

First Author: Amirpiran Amiri

Order of Authors: Amirpiran Amiri; Vijay Periasamy; Moses Oludayo Tade, PhD; Khaliq Ahmed; Gordon D Ingram; Vishnu Pareek; Ranjeet Utikar

Abstract: The simulation of a solid oxide fuel cell (SOFC) that incorporates a detailed user-developed model was performed within the commercial flowsheet simulator Aspen Plus. It allows modification of the SOFC's governing equations, as well as the configuration of the cell's fuel-air flow pattern at the flowsheet level. Initially, the dynamic behaviour of single compartment of a cell was examined with a 0D model, which became the building block for more complex SOFC configurations. Secondly, a sensitivity analysis was performed at the channel (1D) scale for different flow patterns. Thirdly, the effect of fuel and air flow rates on the predominant distributed variables of a cell was tested on a 2D assembly. Finally, an optimisation study was carried out on the 2D cell, leading to a robust, optimal air distribution profile that minimises the internal temperature gradient. This work forms the foundation of future stack and system scale studies. 


\title{
Solid oxide fuel cell reactor analysis and optimisation through a novel multi-scale modelling strategy
}

\author{
Amirpiran Amiri ${ }^{1}$, Periasamy Vijay ${ }^{1}$, Moses O. Tadé ${ }^{* 1}$, Khaliq Ahmed ${ }^{2}$, Gordon D. Ingram ${ }^{1}$, Vishnu \\ Pareek $^{1}$, Ranjeet Utikar ${ }^{1}$ \\ ${ }^{1}$ Centre for Process Systems Computations, Department of Chemical Engineering, Curtin University, \\ GPO Box U1987, Perth WA 6845 \\ ${ }^{2}$ Ceramic Fuel Cells Ltd., Noble Park, Victoria 3174, Australia \\ *Corresponding Author. Telephone: +61-8-9266-7581. Fax: +61-8-9266-2681. Email: \\ m.o.tade@curtin.edu.au
}

\begin{abstract}
The simulation of a solid oxide fuel cell (SOFC) that incorporates a detailed user-developed model was performed within the commercial flowsheet simulator Aspen Plus. It allows modification of the SOFC's governing equations, as well as the configuration of the cell's fuel-air flow pattern at the flowsheet level. Initially, the dynamic behaviour of single compartment of a cell was examined with a OD model, which became the building block for more complex SOFC configurations. Secondly, a sensitivity analysis was performed at the channel (1D) scale for different flow patterns. Thirdly, the effect of fuel and air flow rates on the predominant distributed variables of a cell was tested on a 2D assembly. Finally, an optimisation study was carried out on the 2D cell, leading to a robust, optimal air distribution profile that minimises the internal temperature gradient. This work forms the foundation of future stack and system scale studies.
\end{abstract}

Keywords: Solid Oxide Fuel Cell, Aspen Plus, Multi-Scale, Optimisation, Modelling 


\section{Introduction}

Over the last few decades, worldwide energy demand has shown a dramatic increase due to population growth, industrial development and consumer behaviour. Contemporarily, societal concerns and environmental regulations have also significantly changed, forcing energy producers and consumers to seriously reduce their creation of greenhouse gas pollutants, including carbon and nitrogen oxides. Despite the wide range of industrial and academic research efforts being undertaken to enhance pollutant gas capture technologies, a proven methodology that can guarantee environmental obligations is not yet commercially available. Therefore, clean energy generation technologies have received tremendous attention as they offer a more fundamental solution.

Fuel cell technology is a promising alternative to traditional energy conversion techniques due to its high conversion efficiencies leading to cleaner exhaust emissions. Furthermore, this technology offers a flexible selection of fuels, ranging from renewable resources to fossil fuels; for example, biomass and natural gas, respectively (Aguilar et al., 2004; Lu and Schaefer, 2004; Lin et al., 2005; Ahmed and Föger, 2010; Doherty et al., 2010; Danilov et al., 2011a). Fuel cells find use, in commercial or prototype form, as power systems for transportation (buses, ferries, aircraft), in portable consumer (cameras) or military (portable soldier power) devices, in combined heat and power systems, and for standalone power generation for commercial and residential establishments. The application of this technology, however, is not yet well commercialised due to high manufacturing costs and maintenance requirements. Commercialisation of solid oxide fuel cell (SOFC) technology is highly dependent on the synthesis, configuration and application of advanced materials, because such small scale phenomena ultimately influence the functioning of the whole process. However, attention also needs to be focused at the system scale for overall process design and optimisation purposes, as the balance of plant (BOP) has, in turn, a strong impact on cell scale behaviour and maintenance requirements. From the modelling point of view, there is a bidirectional exchange of information between a single reactor compartment (micro-scale) and the overall system (macro-scale) that cannot be efficiently established without having practical, numerically reliable models at these extreme scales and at intermediate ones. Some previous work has created models that span the different scales of the system through multi-scale strategies (Andersson et al., 2010; Bessler, 2011), but more fundamental and applied research and development effort is still needed at the various process scales to support the commercialisation of the technology.

A comprehensive model of SOFC behaviour involves numerous complex phenomena, including reaction and transport phenomena, catalyst characteristics, thermal and mechanical properties of the materials and electrochemical processes. It is a 'multi-physics' problem. As a result, the application of detailed, mechanistic models requires complex mathematical and numerical algorithms, whilst end 
users, particularly industrial ones, usually seek convenient, integrated modelling and simulation tools: modular process simulators, for instance. Despite some limited work published in this area (Zhang et al., 2005; Doherty et al., 2010; Kattke and Braun, 2010; Ameri and Mohammadi, 2011), demonstrations of system scale modelling and simulation of SOFCs using commercial simulation packages are scarce. Unfortunately, the current widely used, commercial process simulators, including Aspen Plus and Aspen HYSYS, do not include an inbuilt module for a SOFC unit (Zhang et al., 2005) that covers the associated transport and reaction phenomena (Hussain et al., 2007; Ho et al., 2009). There are several reasons for this situation. Firstly, SOFCs are considered to be novel reactors that are the subject of ongoing rigorous experimental and modelling research (Colpan et al., 2008). Research results frequently reveal new aspects of SOFCs that should be accounted for in comprehensive modelling and simulation work. These quickly evolving SOFC designs and SOFC models are not stable enough and mature enough to be embedded as standard blocks in well-known process simulators, such as a Continuous Stirred Tank Reactor (CSTR) or a Plug Flow Reactor (PFR). Secondly, in contrast to the common rigorous and shortcut reactor models, applications of SOFCs are restricted to a narrow field of process engineering and energy conversion technologies. This is possibly another cause for them receiving little attention by process simulator developers, compared to that allocated to conventional reactors. Thirdly, material characteristics, electrochemical reaction kinetics and catalysis are striking and complicated phenomena affecting SOFC behaviour (Tietz et al., 2008; Ho et al., 2010) and the standard reactor units in process simulators are not powerful and flexible enough to tackle these complexities.

The SOFC simulation work presented in this paper provides a foundation for future research and commercialisation studies. Some of the new aspects of this work include: creation of a detailed, compartment scale SOFC block in a commercial process simulator; demonstration of the new and convenient configurability of the block for $0 \mathrm{D}, 1 \mathrm{D}$ and $2 \mathrm{D}$ simulations that aims to capture the internal, distributed SOFC variables in different dimensions; development of a novel capability for co-current, counter-current and cross-current fuel-air flow patterns to be modelled in a flowsheeting environment; and illustration of the use of current, inbuilt process analysis facilities for sensitivity and optimisation studies of a SOFC reactor, for example to find the air flow distribution that minimises cell temperature gradients. The context and significance of these contributions are expanded upon below.

With regard to the available commercial simulators, the modelling library for fuel cell reactors, SOFCs in particular, is still in its infancy. The compartment scale Aspen Custom Modeller (ACM) SOFC building block created in the current project has the potential to form the basis of a comprehensive SOFC modelling library in current process simulators. This approach has two strong advantages. It is easy to change and upgrade any details at the smallest scale of the fuel cell model 
by modifying the ACM code. That is, it is completely flexible. Simultaneously, all the benefits of a commercial process simulator are also available: rigorous thermodynamics calculations, a comprehensive unit model library, ease of placing and configuring units and streams in a flowsheet, and inbuilt tools for performing optimisation, sensitivity studies and so on.

The compartment scale ACM model that is exported to Aspen Plus is the building block for larger scale models. It assumes perfect mixing of both fluid phases. Any desired flow pattern of the fuel and oxidant streams at the larger channel, cell and stack scales, including co-, counter- and crosscurrent flows and any combination of them, can easily be approximated by connecting together multiple ACM blocks in an appropriate configuration on the Aspen Plus flowsheet. No extra programming is needed. Furthermore, by having a detailed, programmed ACM block that encompasses the cell's electrochemical variables and parameters, the simulation of the fuel cell as an ideal PFR, or an even more realistic reactor, becomes feasible by simply connecting blocks in series where the number of repetitive element will be appropriately estimated based on residence time distributions.

The present model not only provides information about the cell outlet streams, but also presents detailed internal information on the operation, flows and electrical properties in the anode, cathode and electrolyte regions. In addition, either internal or external fuel reformer simulation is feasible. The fuel processing aspect has not been simulated in the present study, but the potential approaches are briefly examined here. An external reformer could be simulated by using a currently available standard reactor block. Internal reforming can be implemented through two approaches: (i) direct internal reforming (DIR) by modification of the ACM code so that it includes the reforming and gas shift reaction rates and enthalpies, with these reactions occurring on the surface of the anode; or (ii) indirect internal reforming (IIR) through linking each current ACM block, which does not include reforming, with its own standard reactor block that handles the fuel reforming reactions.

In the following parts of this paper, based on the developed ACM compartment model, a fuel cell reactor is explored on three scales. A dynamic study of a single well-mixed compartment is conducted for testing the model implementation and to reveal its response characteristics at the compartment scale. The role and impact of dominant process variables on steady state channel scale performance is investigated by approximating a channel by several compartments in series. This investigation helps inform the choice of cell configuration, objective function and design variables for use in a subsequent optimisation study at the 2D cell scale, which is approximated by linking multiple channels together.

\section{Modelling framework}


Any process that involves a fuel cell reactor behaves as a multi-scale system. Therefore, both comprehensive individual scale modelling as well as data exchange between the various scales of interest according to an appropriate modelling framework are important. For fuel cell processes, the temporal and spatial scales are very wide. Furthermore, a vast range of reaction and transport phenomena are involved. For example, the key electrochemical reaction between hydrogen and oxygen takes place, along with fuel reformation reactions like the water-gas shift reaction and steam reforming of hydrocarbons. All these are surface reactions requiring a catalyst surface site for activation. Although a comprehensive and applied model should cover the majority of these aspects, the final model should also offer optimum computational performance and convenience to the end user. Being user-friendly is always a goal in simulator development. In this work, we aimed to find a good trade-off between performance and convenience by combining numerical and process flowsheet packages.

Figure 1 displays the communication between the various packages and models used in the current work and also planned for future stages of the same project. In this plan, the effectiveness and ease of process calculations were emphasised without compromising modelling accuracy. In terms of the development of the work, initially a well-mixed reactor model consisting of the main governing and constitutive equations for a single SOFC compartment has been programmed and tested in the ACM environment. This part of the project enables us to capture the electrochemical and thermal details of a fuel cell's internal workings in the Aspen Plus environment. Different voltage losses and internal temperatures can be estimated in the current work for anode, cathode and electrolyte sections separately.

In the second part of the work, an ACM model was exported and made accessible as a new reactor block in the model library within Aspen Plus. The exporting was done through $\mathrm{C}++$ file generation. The model in Aspen Plus operates interactively with the ACM code and all user-machine interfaces are similar to the standard flowsheet blocks. All of the cell's parameters and variables that are defined in the ACM program are accessible through the Aspen Plus data sheet, offering flexibility and convenience for changing the parameter values. A typical 1D SOFC channel was then approximated by six compartments in series, and a $2 \mathrm{D}$ cell was created by linking five channels together with a cross-current flow of air. Any other configuration of compartments and air-fuel flow patterns is also possible and easy to implement. This flexibility, combined with residence time distribution (RTD) functions, can be used to simulate ideal CSTR and PFR reactors, as well as any reactor that falls between these two ideals (Levenspiel, 1999). These capabilities were not available in prior studies (Doherty et al., 2010; Kattke and Braun, 2010; Ameri and Mohammadi, 2011), since only the simulator's inbuilt reactor modules were used. 
Despite not being covered in this paper, the final target, as shown in Figure 1, is to use the detailed SOFC block within a 3D stack embedded in a process flowsheet for analysis and optimisation purposes at the system scale.

\section{Model and parameters}

The governing conservation and constitutive equations for SOFC modelling are strongly dependent on the modelling assumptions and goals. This fact results in a wide range of modelling approaches, ranging from 'steady and lumped' models to 'dynamic and 3D' ones (Kakaç et al., 2007; Bhattacharyya and Rengaswamy, 2009). There must be a good reason to choose a complicated model; otherwise a simple one should be preferred. For instance, while steady state models are efficient and adequate for process rating analysis under normal operating conditions, a dynamic model is required for controller tuning and process commissioning purposes. As the main goal of the work in this paper is to establish a representative simulation of a SOFC for flowsheeting purposes, a 'lumped and dynamic' approach has been used for the single compartment model to keep solution times modest while capturing some transient performance details. Consequently, a single compartment consists of three lumped (0D) regions for the anode, the cathode and the electrolyte to capture the details of the cell internals. Even though the model is OD at the compartment scale, it becomes a 1D, 2D and 3D model at the channel, cell and stack scales, respectively, as shown in Figure 1. The governing conservation and constitutive equations are taken from Hosseini et al. (2010) and Danilov et al. (2011b) and adapted for a single compartment. The model parameters and operating conditions are the same as those used in Hosseini et al. (2010). The model equations and the simulation parameters are summarised in Tables A1 and A2.

\section{Compartment scale dynamic analysis}

Micro-scale compartment modelling is essential as it is the scale that captures the reaction and electrochemical mechanisms. The insights that can be achieved through this dynamic, mechanistic model are significantly greater than those that can be achieved with only the inbuilt, non-dynamic, standard reactor models used for SOFC simulation in the literature (Zhang et al. 2005; Ameri and Mohammadi, 2011). Detailed examination and validation of the compartment scale model is necessary to provide a trusted foundation for the construction of higher scale models, including the integrated multi-scale SOFC model. Furthermore, the predicted behaviour of a full scale SOFC is strongly dependent on that of its sub-models, which are connected through a model integration framework. In this work, particularly, the compartment scale is also the essential bridge between the 
electrochemical reaction, heat transfer and mass transfer phenomena and the higher model scales where process assessment will be carried out. It should be noted that a single compartment can be used to represent a SOFC in a process flowsheet if a OD model for this reactor is desired. In summary, analysis of the compartment model's behaviour is important.

A vast range of dynamic investigations is possible, but only the dynamic response of the compartment model to perturbations in the cell's fuel and air intakes are presented in this paper. These analyses were executed in the ACM environment to verify the ACM implementation and to demonstrate this highly nonlinear model's features in dynamic investigations. Extensive simulation and sensitivity analysis of the SOFC compartment model is outside the scope of this study because many other works have been published at this scale. The essential model used in this research was validated by Hosseini et al. (2010) and Danilov et al. (2011b).

Perturbations in both the air and fuel flow rates result in dynamic thermal behaviour of the cell through affecting the rates of heat generation through reaction and heat removal from the system. The importance of each of these mechanisms, however, is not necessarily equal as will be quantitatively described below. The response of the compartment temperature to step changes in the air and fuel flow rates are presented in Figures 2 and 3, respectively.

It is well known that the oxidant normally does not have a reaction controlling role as it is always available in excess. Accordingly, it impacts the cell temperature mainly via the heat removal mechanism. In Figure 2, the dynamic response of the deviation in the cell temperature $(\Delta T)$ to stepwise changes in the air flow rate $( \pm 10 \%$ variation from the base case value $)$ is presented. The thermal behaviour of the cell is similar to a CSTR having a stepwise change in the coolant stream flow rate. The reactor reaches a new steady temperature after a delay. There is no overshooting of the final temperature. Another point is that the $10 \%$ increase and decrease in the air flow from the base case value does not cause the same cell temperature variation: they cause $5.5 \mathrm{~K}$ and $7 \mathrm{~K}$ deviations, respectively. Even though this observation has its root in the nonlinear nature of the model, it can be explained by the minor role of a higher flow rate of oxidant generating more heat through promoting the reaction rate. A similar scenario has been examined for the fuel flow rate changes. The main difference in the temperature profile dynamics, Figure 3, in contrast to that of air case, is the sudden overshoot observed, which can be attributed to the reactant's impact on the reaction rate and consequently on the heat generated by the reaction. This is an important observation about cell temperature instability due to air and fuel stream fluctuations. Further, unequal temperature deviations from the base case are observed while the reactant flow rate increase and decrease are equal. The role of convective heat removal by the fuel steam becomes greater at higher fuel rates. In spite of this, the final steady temperature is higher for higher reactant flow rates. This unequal 
response of the cell temperature to the changes in the air flow rate will have implications for cell temperature control, as controllers designed or tuned with linear model assumptions may not be sufficiently effective.

\section{Channel scale sensitivity analysis}

Two key advantages of the simulation approach outlined in this work are that a wide range of sensitivity analyses can be conducted over a spectrum of scales with little or no extra programming, and they can be performed within an established modular simulator. Previously this has not been possible for SOFCs. Aspen Plus contains a sensitivity analysis facility that can be used on any novel model imported into its environment. The present user-defined model of a SOFC has been tested for sensitivity analysis purposes and has been found to be highly flexible. For instance, the effect of fuel flow rate increase, up to two times the base value, on the performance of the cell has been parametrically investigated through monitoring of operating variables including the fuel utilization, current density and temperature distributions for different fuel-air flow configurations (Figures 4-9). For the first time, this study focuses on a single channel formed by connecting the fuel streams of six compartment models in series, with three different air stream configurations, to illustrate the capabilities for 1D process modelling and analysis of a SOFC reactor in the Aspen Plus environment. Note that the simulation parameters used for these channel scale studies are those reported in Table A2 and the choice of six compartments in series is discussed in Appendix B.

\subsection{Effect of fuel flow rate on fuel utilization}

For each compartment, fuel utilization $\left(U_{F}\right)$, a key SOFC performance characteristic, is defined as:

$$
U_{F}=1-\frac{y_{o u t}^{f_{s}} F_{o u t}^{A}}{y_{\text {in }}^{f_{s}} F_{\text {in }}^{A}}
$$

where $F_{\text {in }}^{A}$ and $F_{\text {out }}^{A}$ are the fuel stream's inlet and outlet molar flow rates, and $y_{\text {in }}^{f_{s}}$ and $y_{\text {out }}^{f_{s}}$ are the fuel species' inlet and outlet mole fractions, respectively. The prediction of fuel consumption, which requires the simultaneous solution of the non-linear compartment model equations in Table A1, depends on the reaction rate, which is itself dependent on the local fuel concentration and temperature. Therefore, a higher fuel flow rate affects fuel utilization in a nonlinear way. This effect has been studied for different flow patterns as can be seen in Figure 4. Note that compartment number 
1 corresponds to the location of the fuel inlet, and the Fuel Flow Rate Ratio is the ratio of the actual inlet fuel flow rate for the case considered to the base case inlet fuel flow rate given in Table A2.

Generally the trends in the local fuel utilization profile are similar for all flow configurations. At higher fuel rates a lower fuel utilization and lower gradient in the profiles is observed. The lower gradient results from having a higher excess of reactant and a flatter temperature profile. While higher fuel utilization, up to a certain limit, is always of interest, having a non-uniform $U_{F}$ profile implies similar gradients in the temperature and current density profiles, which are undesirable. Therefore, there is an inevitable trade-off between fuel utilization and uniformity of conditions inside the fuel cell.

The fuel utilization profiles shows a higher gradient along the channel length for co-current fuel-air flow compared to other two cases. Moreover, in spite of the similarity between the counter- and crosscurrent patterns, the latter shows higher fuel utilization under all fuel flow rates, particularly at the higher rates as shown. To emphasise the difference in $U_{F}$ for these flow patterns, the fuel utilization ratios, $U_{F \text { cross-current }} / U_{F \text { counter-current }}$ and $U_{F \text { cross-current }} / U_{F \text { co-current }}$, are compared for the flow patterns as shown in Figures 4(C) and 4(D), respectively. The fuel utilization and temperature profiles are interconnected; the $U_{F}$ trends will be further discussed when the temperature profiles are presented in Section 5.3.

\subsection{Effect of fuel flow rate on current density distribution}

Current density and its distribution is another measure of a cell's performance that a comprehensive model must be able to predict. This characteristic is examined for different fuel flow rates and the results are displayed in Figure 5. The current density is increased by fuel flow rate for all compartments for the three flow patterns. In addition, the profiles are smoother for higher flow rates. However, the location of the observed peak in current density may change with the fuel flow rate. Furthermore, there is a similarity between the current density trends of the counter- and cross-current configurations, but detailed comparison of the values shows significant differences, particularly at low fuel flow rates as emphasised in Figure 6. The current distribution is a highly nonlinear function of local hydrogen conversion and the latter is affected by the spatially varying temperature. Any variation in these dominant variables drives the changes in the produced current.

\subsection{Effect of fuel flow rate on temperature profile}

The temperature profile along the channel length is significantly different for the three flow patterns studied in this work because of the dominant effect of the air stream on convective heat transfer inside the system. A thermally homogenous system is always desired for fuel cell operation to avoid potential mechanical and operational malfunctions. As can be seen in Figure 7, the cross-current 
configuration shows lower temperature gradients compared to the other two patterns. Due to its importance in a cell's thermal management, this configuration will be the focus of the cell optimisation study reported in the next section.

These temperature profiles help to explain the differences in the fuel utilization results reported in Figures 4(A) and 4(B). It can be seen that a higher average temperature improves the average fuel utilization and, in turn, higher conversion increases the temperature. This interaction is mutual and nonlinear. Even though the temperature profile for cross-current flow is not flat, its average over the channel length is higher than other two patterns. The same behaviour can be seen for fuel utilization in the cross-current flow regime compared to other two (Figures $4(\mathrm{C})$ and $4(\mathrm{D})$ ). Where the temperature profile of the cross-current flow falls below that of co-current flow, the fuel utilization profiles also cross each other. Note that in this analysis, the same total air flow rate was used in the three flow patterns. In cross-current flow, each compartment receives fresh, low temperature air, and the total flow is divided equally among the six compartments involved.

\section{Cell scale sensitivity analysis}

Practical analysis of the behaviour of a cross-current cell must be carried out in two dimensions. The cross-current flow pattern is potentially suitable for cell thermal management through manipulation of the air flow distribution. Therefore, to provide the groundwork for this possibility, sensitivity analysis was conducted on the 2D cross-flow cell in Figure 8. The main goal of the study was to see the effect of fuel and air flow rates on the spatial variation of several key variables inside the cell and also on the overall performance of the cell.

To quantify the spatial variations for several key distributed variables $D \in\left\{I, T, y_{H_{2}}, E^{O C V}\right\}$, the average values $(\bar{D})$ and coefficients of variation $\left(C V_{D}\right)$, or standard deviation divided by the mean, were calculated using the following equations:

$$
\begin{aligned}
& \bar{D}=\frac{1}{S} \sum_{j=1}^{m} \sum_{i=1}^{n} S_{i, j} D_{i, j}=\frac{1}{m n} \sum_{j=1}^{m} \sum_{i=1}^{n} D_{i, j} \\
& C V_{D}=\sqrt{\frac{1}{S} \sum_{j=1}^{m} \sum_{i=1}^{n} S_{i, j}\left(\frac{D_{i}-\bar{D}}{\bar{D}}\right)^{2}}=\frac{1}{\bar{D}} \sqrt{\frac{1}{m n} \sum_{j=1}^{m} \sum_{i=1}^{n}\left(D_{i}-\bar{D}\right)^{2}}
\end{aligned}
$$

where $j$ is the channel number, $i$ is the number of the compartment within channel $j, m$ is the number of channels, $n$ is the number of compartments per channel, $S_{i, j}$ is the area of compartment $(i, j), S$ is the 
total area of the cell, $D_{i, j}$ is the value of $D$ in compartment $(i, j)$, and it is assumed that all cells have the same size.

\subsection{Effect of fuel flow rate at constant air flow rate}

The cell's distributed variables are interconnected through highly nonlinear relations. Therefore, interpreting the cause-effect relationships in the modelling results can be challenging. In this part of the study, the effect of fuel flow rates $10 \%$ higher and 10\% lower than the base case value are investigated for their influence on the temperature, current density, hydrogen mole fraction and Nernst voltage while the air flow rate was kept constant at the base case value. The cell is operated in constant voltage mode with $E_{\text {cell }}=0.80 \mathrm{~V}$ as shown in Table A2. The results of this sensitivity study are displayed in Figure 9 with numerical values reported in Table 1.

The 2D temperature distributions plotted in Figure 9 show only small changes with an increase in the fuel flow rate. Numerical results presented in Table 1 show that the average temperature over the cell surface is increased by about $10 \mathrm{~K}$ when the fuel flow rate changes from $-10 \%$ to $+10 \%$ of the base case value. It might be concluded that the heat generated by the reaction due to the fuel increase outweighs the heat removed by the flow of this stream. The higher fuel rate also results in a higher spread in the temperature distribution as characterised by the coefficient of variation of the temperature (Table 1). This indicates that the reaction rate is not promoted equally in all parts of the cell by providing more fuel. This is also illustrated by the increasing difference between the "hot spot" and "cold spot" temperatures, $\max \left(T_{i, j}\right)-\min \left(T_{i, j}\right)$, which changes from 265.0 to $278.8 \mathrm{~K}$ for the lowest and highest fuel rates, respectively. It should be noted that the locations of the hot and cold spots do not change, as can be seen in Figure 9. Even though the cooling role of the fuel stream is not often emphasised in the analysis of hydrogen fuelled SOFC processes, purposefully adjusting the fuel stream composition, rather than using pure hydrogen, could potentially be a useful extra design option.

Increasing the fuel flow rate increases both the average temperature and the hydrogen mole fraction in all parts of the cell, which has a positive influence on the electrochemical reaction. Therefore, the generated current density benefits and is improved by about $18 \%$ when the lowest and highest fuel rates are compared. Interestingly, the coefficient of variation of the current density is also lowered by increasing fuel rate even though the current peak becomes more pronounced. This is in contrast with the thermal behaviour and could be interpreted by considering the role that hydrogen plays. With higher fuel rates the hydrogen distribution becomes more even: its coefficient of variation decreases from 0.8274 to 0.7541 . It must be noted that fuel utilization always decreases at higher feed rates, but this does not necessarily lead to lower generated current or heat, as the inlet fuel rate is varying. In investigating scenarios with different fuel flow rates, consideration of the total amount of consumed 
hydrogen is more appropriate for evaluation of the generated heat and current, while fuel utilization is a suitable indicator of the possibility of fuel waste in these cases.

Nernst voltage is a function of local temperature and concentration. The peak voltage can be observed where the temperature is low and the hydrogen concentration is high.

\subsection{Effect of air flow rate at constant fuel flow rate}

With the fuel flow rate kept constant at the base case value, the influence of air flow rate on the cell's behaviour was investigated for three different air flows and the results obtained are shown in Figure 10 and Table 2.

As a preliminary finding, the higher air flow rates reduce the thermal inhomogeneity in the cell, while the average temperature of the cell also considerably decreases because of the higher heat removal rate. Increased air flow lowers the temperature and the Nernst voltage increases as a consequence. To maintain the operation at a constant cell voltage, the current is reduced and, as a result, fuel utilization is also reduced.

While the impact of the fuel flow rate was more significant on the cell's overall performance in terms of current production and fuel consumption, the air stream, in contrast, mostly influences the position and spread of the peaks in the distributed variables over the cell's surface. For instance, increasing the air flow rate caused the peak of the current density to be lowered and shift from the middle of the cell's inlet to the hot side of the inlet. The higher the temperature and hydrogen concentration, the higher the current density produced due to promotion of the electrochemical reaction. Therefore, the current density profile is dominated by the temperature and hydrogen distributions.

Even though a higher air flow rate offers a smoother internal temperature profile, its negative side effects on the cell performance, such as the fuel utilization and power produced, are significant, as described in the literature (Halinen et al., 2010; Di Carlo et al., 2013). More importantly the higher air flow rates cause higher operating costs as greater power is consumed in providing the required flow rate (Di Carlo et al., 2013).

\section{Cell scale optimisation study}

The maintenance and effective working life of a cell, which are critical issues for SOFC commercialisation, are strongly dependent on its thermal management history. Any inhomogeneity in the temperature distribution influences the temperature dependent parameters, which may amplify the thermal gradient in turn. For instance, the local ion conductivity grows as temperature increases, thus 
the current density increases at that particular location. The higher current density drives the reaction and generates more reactive heat that leads to an increase in temperature (Mangold et al., 2004). The manipulation and optimisation of the air flow rate is one of the most effective strategies for setting up and controlling an appropriate temperature distribution over the cell's commissioning, operation and shutdown stages. The oxidant needed for the electrochemical reaction is also provided by the air stream. The negative consequences of high air flow rates were mentioned in the previous section. On the other hand, a very low flow rate of air may cause air starvation in parts of the cell in addition to undesirable gradients in the distributed variables. Therefore, optimising the air distribution inside the cell for a moderate total flow rate is a promising way to enhance the cell's thermal behaviour while avoiding the disadvantages of very high or low air intakes.

Fuel cell optimisation consists of solving a minimisation problem for the objective function subject to equality and inequality constraints. The objective function depends on a set design variables, which can vary in a certain range (Secanell et al., 2011).

An air distribution optimisation case study for a cell with a cross-current flow pattern has been implemented in Aspen Plus using the 2D model (Figure 8). The air stream might be fed into the cell's air channels either uniformly or non-uniformly. The first option offers simplicity and ease in cell manufacturing. Alternatively, an optimised air flow could potentially result in enhancement of the cell's operation in terms of its thermal performance and homogeneity of the current production. Note that the 2D modelling and simulation of a SOFC in Aspen Plus and also the use of this package for SOFC optimisation purposes are novel aspects of this study. The parameters presented in Table A2 were used as the basis of this simulation.

A cell with 30 compartments was considered in this case study. The air intake flow rate for each air channel must be optimised, aiming to minimise the temperature gradient over the cell surface. Therefore, the minimum difference in temperature between adjacent compartments is considered as the objective function, $f$, and it is to be obtained by manipulating the air flow distribution by using split fractions in splitter block $B 1$ shown in Figure 8:

$$
\min f=\frac{1}{2 n m \bar{T}}\left[\sqrt{\sum_{j=1}^{m} \sum_{i=1}^{n-1}\left(T_{i, j}-T_{i+1, j}\right)^{2}}+\sqrt{\sum_{i=1}^{n} \sum_{j=1}^{m-1}\left(T_{i, j}-T_{i, j+1}\right)^{2}}\right]
$$

subject to:

\section{$10 \%<$ flow fraction $<30 \%$}

where $\bar{T}$ is the cell's mean temperature and $T_{i, j}$ is the temperature in compartment $(i, j)$. The optimisation constraints on the flow fraction were put in place to avoid large changes in the cell 
current density, fuel utilization and other process variables. Note that the flow fraction in the nonoptimised case of uniform air flow distribution is $1 / 6$ or 0.1667 . The optimisation was conducted using Aspen Plus' inbuilt optimisation capabilities, which employ sequential quadratic programming for simultaneous optimisation and flowsheet convergence (Aspen Technologies, 2013). The objective function was defined as usual with a FORTRAN statement within Aspen Plus.

Figures 11 displays the PEN temperature profiles and other distributed variables of interest over the cell for both non-optimised (uniform) and optimised (non-uniform) air intake flow rates. The uniform distribution results show good agreement with the profiles predicted by Selimovic et al. (2005) and Chyou et al. (2005) for the cross-current configuration with adiabatic boundaries. Some temperature gradients are still present in the optimised case, but overall the temperature profile has been smoothed by optimising the air flow rate distribution in splitter block $B 1$. The temperature distribution for the uniform air flow case shows significant differences in different locations of the cell, particularly with the hot spot formation near the fuel inlet. Under the optimised conditions, the air channels FC51-A, FC52-A, FC53-A, FC54-A, FC55-A and FC56-A shown in Figure 8 receive $23.13 \%, 18.70 \%, 16.83 \%, 15.27 \%, 13.82 \%$ and $12.25 \%$, respectively, of the total air flow entering the fuel cell (the $A F$ stream in Figure 8). It should be noted that none of the split fractions are at the limits (10-30\%) set up in the optimisation problem. The objective function value is $f=0.023$ in the optimised case in contrast to 0.051 for non-optimised case. The optimisation procedure converged in 17 iterations. While the temperature difference between the cold spot and hot spot is $271 \mathrm{~K}$ in the non-optimised case, it is moderated by optimised air flow to $154 \mathrm{~K}$.

As can be seen in Figure 11 and also from the results in Table 3, while the improvement in the temperature distribution can be considered as the main achievement of the optimisation, the homogeneity of the current density distribution has also been improved as its coefficient of variation shows has been significantly reduced. The average current density, however, shows a slight decrease due to the optimised air distribution, which is reflected in a small reduction in the fuel utilization. This might be due to lowering the reaction rate by moderating the temperature at locations where the hydrogen availability is higher (at the fuel entrance) to the places where this reactant concentration is lower (neat the fuel exit). Fortunately this effect is minor.

The main source of heat generation in each compartment is the electrochemical reaction. Management of the reaction rate through control of the fuel availability is a potential manipulated variable that could be used to achieve the cell's thermal management goals. However it should be noted that the PEN temperature is also influenced by the inlet and outlet flow rates of each compartment. To further this investigation, the fuel distribution between channels was changed to see if a smoother temperature profile could be achieved by intentionally providing less fuel to hot 
locations of the cell. For instance, compartment FC11, which possesses the highest temperature (Figures 9 and 10), was targeted to receive less hydrogen flow in comparison to compartment FC51. This was done for other compartments and channels too. However, the analysis revealed that this strategy could not significantly influence the temperature distribution for the cross-current pattern. This could be attributed to two reasons. Hotspots will always occur near where the fresh feed enters a channel as the hydrogen concentration is at its highest there and is above the level that would potentially control the reaction rate by limiting the reactant availability. In addition, a lower fuel flow rate means that there is less capacity for the flow of the stream to transport energy from the compartment, and hence the temperature rise cannot be moderated.

As a further investigation, effect of fuel flow rate on the optimised air flow profiles was tested. Accordingly, the optimisation was repeated for several fuel flow rates and the optimum air distribution profile was captured as shown in Figure 12. Note that the total air flow rate was constant at the base case value, and the range of fuel flow rates investigated was intentionally selected to be very wide to test the robustness of the predicted optimised air profiles. The air profiles are reasonably similar in shape for the fuel flow rates investigated and show that more air is needed close to the fuel inlet. Moreover, the optimised air profiles change little for a very wide range of fuel flow rates, which suggests that manufacturers could build a simple air distributor that performs optimally for a relatively wide range of fuel flows. To achieve the desired air flow profile, one possibility is to manufacture different orifice sizes at the entrance of each air channel.

\section{Conclusions}

As a part of an investigation into the multi-scale modelling of a SOFC system, the simulation of a SOFC at the compartment (0D), channel (1D) and cell (2D) scales was carried out. The simulations were implemented by a combination of numerical and process flowsheeting packages and were able to achieve more insight into a cell's performance than could be obtained by using only the inbuilt blocks available in well-known process simulators such as Aspen Plus. The proposed multi-scale modelling platform was successfully implemented up to the cell scale, providing a convenient, modular basis for developing planned stack and system scale SOFC process simulations. The model has been parametrically tested. First, a single compartment's dynamic behaviour was explored. This was followed by a sensitivity analysis of a single channel's performance under different fuel flow rates and flow patterns. Finally, sensitivity analysis and thermal optimisation at the cell scale was presented, showing the effectiveness of the modular flowsheet approach for finding the best air flow distribution. The mathematical model of a single compartment has already been validated against experimental data in the literature by some of the co-authors of this paper. In future work, the detailed 
simulation block developed in this work will be used to create a rigorous and reliable system scale simulation that can be used for design and optimisation studies.

\section{Nomenclature}

\begin{tabular}{|c|c|}
\hline$C_{d L}$ & Double layer capacitance $\left(\mathrm{A} \mathrm{s} \mathrm{V}^{-1} \mathrm{~m}^{-2}\right)$ \\
\hline$C_{h}$ & Channel height (m) \\
\hline$C_{p}$ & Specific heat $\left(\mathrm{J} \mathrm{mol}^{-1} \mathrm{~K}^{-1}\right)$ \\
\hline$D_{298}^{s}$ & Species effective mass diffusivity coefficient at $298 \mathrm{~K}\left(\mathrm{~m}^{2} \mathrm{~s}^{-1}\right)$ \\
\hline$D_{e f f}^{s}$ & Species effective mass diffusivity coefficient $\left(\mathrm{m}^{2} \mathrm{~s}^{-1}\right)$ \\
\hline$E_{a c t}$ & Activation energy $\left(\mathrm{kJ} \mathrm{mol}^{-1}\right)$ \\
\hline$E_{\text {cell }}$ & Cell voltage (V) \\
\hline$E^{O C V}$ & Open circuit voltage based on the Nernst equation (V) \\
\hline$F$ & Faraday's constant $\left(96485 \mathrm{C} \mathrm{mol}^{-1}\right)$ \\
\hline$F_{\text {in }}, F_{\text {out }}$ & Inlet and outlet molar flow rate $\left(\mathrm{mol} \mathrm{s}^{-1}\right)$ \\
\hline$H$ & Specific enthalpy $\left(\mathrm{J} \mathrm{mol}^{-1}\right)$ \\
\hline$\Delta H_{R}$ & Reaction enthalpy $\left(\mathrm{J} \mathrm{mol}^{-1}\right)$ \\
\hline$I$ & Current (A) \\
\hline$i$ & Current density $\left(\mathrm{A} \mathrm{m}^{-2}\right)$ \\
\hline$i^{*}$ & Pre-exponential kinetics factor $\left(\mathrm{A} \mathrm{m}^{-2}\right)$ \\
\hline$i_{0}$ & Exchange current density $\left(\mathrm{A} \mathrm{m}^{-2}\right)$ \\
\hline$k_{e f f}^{s}$ & Species effective mass transfer coefficient $\left(\mathrm{m} \mathrm{s}^{-1}\right)$ \\
\hline$n_{e}$ & Number of electrons \\
\hline
\end{tabular}




$\begin{array}{ll}q & \text { Energy source term }\left(\mathrm{J} \mathrm{s}^{-1}\right) \\ R & \text { Ideal gas constant }\left(\mathrm{J} \mathrm{mol}^{-1} \mathrm{~K}^{-1}\right) \\ R^{\text {ohmic }} & \text { Ohmic resistance }\left(\Omega \mathrm{m}^{2}\right) \\ r & \text { Mass source term }\left(\mathrm{mol} \mathrm{s}^{-1}\right) \\ S & \text { Cell area }\left(\mathrm{m}^{2}\right) \\ S_{i, j} & \text { Electrode area in compartment }(i, j)\left(\mathrm{m}^{2}\right) \\ T & \text { Temperature }(\mathrm{K}) \\ t & \text { Time }(\mathrm{s}) \\ V & \text { Volume }\left(\mathrm{m}^{3}\right) \\ y & \text { Species mole fraction }\end{array}$

\section{Greek letters}

$\begin{array}{ll}\alpha & \text { Heat transfer coefficient }\left(\mathrm{W} \mathrm{m}^{-2} \mathrm{~K}^{-1}\right) \\ \alpha_{\mathrm{A}}^{\mathrm{A}} & \text { Anodic charge transfer coefficients for anode } \\ \alpha_{\mathrm{C}}^{\mathrm{A}} & \text { Cathodic charge transfer coefficients for anode } \\ \alpha_{\mathrm{A}}^{\mathrm{C}} & \text { Anodic charge transfer coefficients for cathode } \\ \alpha_{\mathrm{C}}^{\mathrm{C}} & \text { Cathodic charge transfer coefficients for cathode } \\ \gamma & \text { Reaction rate exponent } \\ \delta & \text { Catalyst thickness }(\mathrm{m}) \\ \varepsilon & \text { Porosity } \\ \eta & \text { Overpotential }(\mathrm{V}) \\ v & \text { Stoichiometric coefficient } \\ \rho C_{p}^{P E N} & \text { PEN thermal capacity }\left(\mathrm{J} \mathrm{m}^{-3} \mathrm{~K}^{-1}\right) \\ \rho_{m o l} & \text { Molar density }\left(\mathrm{mol} \mathrm{m} \mathrm{m}^{-3}\right) \\ \sigma & \text { Conductivity }\left(\Omega^{-1} \mathrm{~m}^{-1}\right)\end{array}$

\section{Sub/superscripts}


Anode

$\begin{array}{ll}\text { as } & \text { Air } \\ \text { as } & \text { Air species } \\ \text { cat } & \text { Cathode } \\ \text { eff } & \text { Catalyst layer } \\ \text { eq } & \text { Effective } \\ t & \text { Equilibrium } \\ f s & \text { Fuel } \\ \text { gas } & \text { Fuel species } \\ \text { in } & \text { Gas phase } \\ \text { out } & \text { Inlet }\end{array}$

\section{Acknowledgements}

The authors would like to acknowledge the financial support of the Australian Research Council (Grant Number: LP120200622).

\section{References}

Aguilar, L., S. Zha, Z. Cheng, J. Winnick and M. Liu (2004). "A solid oxide fuel cell operating on hydrogen sulfide $\left(\mathrm{H}_{2} \mathrm{~S}\right)$ and sulfur-containing fuels” Journal of Power Sources 135(1-2): 17 24.

Ahmed, K. and K. Föger (2010). "Fuel Processing for High-Temperature High-Efficiency Fuel Cells" Industrial \& Engineering Chemistry Research 49(16): 7239-7256.

Ameri, M. and R. Mohammadi (2011). "Simulation of an atmospheric SOFC and gas turbine hybrid system using Aspen Plus software" International Journal of Energy Research 37(5): 412425.

Andersson, M., J. Yuan and B. Sundén (2010). "Review on modeling development for multiscale chemical reactions coupled transport phenomena in solid oxide fuel cells" Applied Energy 87(5): 1461-1476.

Aspen Technologies (2013). "Aspen Plus Help" in Aspen Plus (Version 8.4) [Software], Aspen Technologies: USA. 
Bessler, W. G. (2011). "Multi-Scale Modeling of Solid Oxide Fuel Cells: From Patterned Anodes to a Power Plant System" ECS Transactions 35(1): 859-869.

Bhattacharyya, D. and R. Rengaswamy (2009). "A Review of Solid Oxide Fuel Cell (SOFC) Dynamic Models” Industrial \& Engineering Chemistry Research 48(13): 6068-6086.

Chyou, Y.-P., T.-D. Chung, J.-S. Chen and R.-F. Shie (2005). "Integrated thermal engineering analyses with heat transfer at periphery of planar solid oxide fuel cell" Journal of Power Sources 139(1-2): 126-140.

Colpan, C. O., I. Dincer and F. Hamdullahpur (2008). "A review on macro-level modeling of planar solid oxide fuel cells" International Journal of Energy Research 32(4): 336-355.

Danilov, V. A., J. Denayer and I. Moon (2011a). “An Improved Tank in Series Model for the Direct Methanol Fuel Cell” International Journal of Electrochemistry doi:10.4061/2011/204937.

Danilov, V. A., P. Vijay and M. O. Tade (2011b). "Improved Tank in Series Reactor Model for Tubular Solid Oxide Fuel Cell Stacks" Chemical Engineering \& Technology 34(5): 737745 .

Di Carlo, A., D. Borello and E. Bocci (2013). "Process simulation of a hybrid SOFC/mGT and enriched air/steam fluidized bed gasifier power plant" International Journal of Hydrogen Energy 38(14): 5857-5874.

Doherty, W., A. Reynolds and D. Kennedy (2010). "Computer simulation of a biomass gasificationsolid oxide fuel cell power system using Aspen Plus” Energy 35(12): 4545-4555.

Halinen, M., J. Saarinen, M. Noponen, I. C. Vinke and J. Kiviaho (2010). "Experimental Analysis on Performance and Durability of SOFC Demonstration Unit” Fuel Cells 10(3): 440-452.

Ho, T. X., P. Kosinski, A. C. Hoffmann and A. Vik (2009). "Modeling of transport, chemical and electrochemical phenomena in a cathode-supported SOFC" Chemical Engineering Science 64(12): 3000-3009.

Ho, T. X., P. Kosinski, A. C. Hoffmann and A. Vik (2010). "Transport, chemical and electrochemical processes in a planar solid oxide fuel cell: Detailed three-dimensional modeling" Journal of Power Sources 195(19): 6764-6773.

Hosseini, S., V. A. Danilov, P. Vijay and M. O. Tadé (2010). "Improved Tank in Series Model for the Planar Solid Oxide Fuel Cell” Industrial \& Engineering Chemistry Research 50(2): 1056-1069.

Hussain, M. M., X. Li and I. Dincer (2007). "Mathematical modeling of transport phenomena in porous SOFC anodes" International Journal of Thermal Sciences 46(1): 48-56.

Kakaç, S., A. Pramuanjaroenkij and X. Y. Zhou (2007). "A review of numerical modeling of solid oxide fuel cells" International Journal of Hydrogen Energy 32(7): 761-786.

Kattke, K. J. and R. J. Braun (2010). "Implementing Thermal Management Modeling Into SOFC System Level Design” Journal of Fuel Cell Science and Technology 8(2): 021009-021009. 
Krewer, U., Y. Song, K. Sundmacher, V. John, R. Lübke, G. Matthies and L. Tobiska (2004). "Direct methanol fuel cell (DMFC): analysis of residence time behaviour of anodic flow bed" Chemical Engineering Science 59(1): 119-130.

Levenspiel, O. (1999). Chemical Reaction Engineering, $3^{\text {rd }}$ ed., John Wiley and Sons: New York.

Lin, Y., Z. Zhan, J. Liu and S. A. Barnett (2005). "Direct operation of solid oxide fuel cells with methane fuel" Solid State Ionics 176(23-24): 1827-1835.

Lu, Y. and L. Schaefer (2004). "A solid oxide fuel cell system fed with hydrogen sulfide and natural gas" Journal of Power Sources 135(1-2): 184-191.

Mangold, M., M. Krasnyk and K. Sundmacher (2004). "Nonlinear analysis of current instabilities in high temperature fuel cells" Chemical Engineering Science 59(22-23): 4869-4877.

Secanell, M., J. Wishart and P. Dobson (2011). "Computational design and optimization of fuel cells and fuel cell systems: A review” Journal of Power Sources 196(8): 3690-3704.

Selimovic, A., M. Kemm, T. Torisson and M. Assadi (2005). "Steady state and transient thermal stress analysis in planar solid oxide fuel cells" Journal of Power Sources 145(2): 463-469.

Tietz, F., A. Mai and D. Stöver (2008). "From powder properties to fuel cell performance - A holistic approach for SOFC cathode development" Solid State Ionics 179(27-32): 15091515 .

Zhang, W., E. Croiset, P. L. Douglas, M. W. Fowler and E. Entchev (2005). "Simulation of a tubular solid oxide fuel cell stack using Aspen Plus ${ }^{\mathrm{TM}}$ unit operation models" Energy Conversion and Management 46(2): 181-196. 
Table 1. Cell performance for different fuel flow rates with air flow rate constant at the base case value.

\begin{tabular}{lccc}
\hline Variable & $\begin{array}{c}\mathbf{A} \\
\text { (Fuel flow rate 10\% } \\
\text { lower than base case) }\end{array}$ & $\begin{array}{c}\text { B } \\
\text { (Base case fuel } \\
\text { flow rate) }\end{array}$ & $\begin{array}{c}\text { C } \\
\text { (Fuel flow rate 10\% } \\
\text { higher than base case) }\end{array}$ \\
\hline Average Temperature, K & 1229 & 1235 & 1239 \\
Temperature Coefficient of Variation & 0.0517 & 0.0522 & 0.0532 \\
Average Current Density, A/m ${ }^{2}$ & 1012 & 1108 & 1195 \\
Current Density Coefficient of Variation & 0.9056 & 0.8482 & 0.8199 \\
Average Nernst Voltage, V & 0.881 & 0.883 & 0.885 \\
Average Hydrogen Mole Fraction & 0.24 & 0.26 & 0.28 \\
Fuel Utilization & 0.92 & 0.90 & 0.88 \\
\hline
\end{tabular}


Table 2. Cell performance for different air flow rates with fuel flow rate constant at the base case value.

\begin{tabular}{lccc}
\hline Variable & $\begin{array}{c}\mathbf{A} \\
\text { (Air flow rate } \\
\text { 20\% lower than } \\
\text { base case) }\end{array}$ & $\begin{array}{c}\mathbf{B} \\
\begin{array}{c}\text { (Base case air } \\
\text { flow rate) }\end{array}\end{array}$ & $\begin{array}{c}\mathbf{C} \\
\text { (Air flow rate 20\% } \\
\text { higher than base case) }\end{array}$ \\
\hline Average Temperature, K & 1265 & 1235 & 1215 \\
Temperature Coefficient of Variation & 0.0663 & 0.0522 & 0.0432 \\
Average Current Density, A/m ${ }^{2}$ & 1113 & 1108 & 1099 \\
Current Density Coefficient of Variation & 0.8854 & 0.8482 & 0.8119 \\
Average Nernst Voltage, V & 0.873 & 0.883 & 0.891 \\
Average Hydrogen Mole Fraction & 0.25 & 0.26 & 0.27 \\
Fuel Utilization & 0.91 & 0.90 & 0.89 \\
\hline
\end{tabular}


Table 3. Cell performance variables under non-optimised (base case) and optimised conditions for the same total air flow rate in both cases.

\begin{tabular}{lcc}
\hline Variable & $\begin{array}{c}\text { Non- } \\
\text { Optimised }\end{array}$ & Optimised \\
\hline Average Temperature, K & 1235 & 1238 \\
Temperature Coefficient of Variation & 0.0522 & 0.0407 \\
Average Current Density, A/m ${ }^{2}$ & 1108 & 1098 \\
Current Density Coefficient of Variation & 0.8482 & 0.7554 \\
Average Nernst Voltage, V & 0.883 & 0.884 \\
Average Hydrogen Mole Fraction & 0.26 & 0.28 \\
Fuel Utilization & 0.90 & 0.89 \\
\hline
\end{tabular}




\section{Appendix A}

Table A1. Model equations for a single compartment of a SOFC.

\section{Component balances}

$$
\begin{aligned}
& \rho_{\text {mol }}^{f} V_{\text {gas }}^{f} \frac{d y^{f_{s}}}{d t}=y_{\text {in }}^{f_{s}} F_{\text {in }}^{f}-y_{\text {in }}^{f_{s}} F_{\text {out }}^{f}-\rho_{\text {mol }}^{f} k_{\text {eff }}^{f_{s}} S\left(y^{f_{s}}-y_{\text {cat }}^{f_{s}}\right) \quad \text { Component balance: fuel channel } \\
& \rho_{m o l}^{a} V_{\text {gas }}^{a} \frac{d y^{a s}}{d t}=y_{i n}^{a s} F_{\text {in }}^{a}-y_{\text {in }}^{a s} F_{\text {out }}^{a}-\rho_{\text {mol }}^{a} k_{\text {eff }}^{a s} S\left(y^{a s}-y_{\text {cat }}^{a s}\right) \quad \text { Component balance: air channel } \\
& \rho_{m o l}^{f} V_{c a t}^{f} \frac{d y_{c a t}^{f_{s}}}{d t}=\rho_{m o l}^{f} k_{e f f}^{f_{s}} S\left(y^{f_{s}}-y_{\text {cat }}^{f_{s}}\right)+r^{f_{s}} \quad \text { Component balance for catalyst layer } \\
& \rho_{\text {mol }}^{a} V_{\text {cat }}^{a} \frac{d y_{\text {cat }}^{a s}}{d t}=\rho_{\text {mol }}^{a} k_{\text {eff }}^{a s} S\left(y^{a s}-y_{\text {cat }}^{a s}\right)+r^{a s} \quad \text { Component balance for catalyst layer }
\end{aligned}
$$

\begin{tabular}{ll}
\hline Energy balances & \\
\hline$\rho_{\text {mol }}^{f} V_{\text {gas }}^{f} C_{p}^{f} \frac{d T^{f}}{d t}=\left(F_{\text {in }}^{f} H_{\text {in }}^{f}-F_{\text {out }}^{f} H_{\text {out }}^{f}\right)+q^{f}$ & Energy balance: fuel channel \\
$\rho_{\text {mol }}^{a} V_{\text {gas }}^{a} C_{p}^{a} \frac{d T^{a}}{d t}=\left(F_{\text {in }}^{a} H_{\text {in }}^{a}-F_{\text {out }}^{a} H_{\text {out }}^{a}\right)+q^{a}$ & Energy balance: air channel \\
$\rho V^{P E N} C_{p}^{P E N} \frac{d T^{P E N}}{d t}=q^{P E N}$ & Energy balance: PEN
\end{tabular}

\begin{tabular}{|c|c|}
\hline$F_{\text {Out }}^{a}=F_{\text {in }}^{a}-\sum \rho_{\text {mol }}^{f} k_{\text {eff }}^{a s} S\left(y^{a s}-y_{\text {cat }}^{a s}\right)$ & Air flow rate change \\
\hline$F_{\text {out }}^{f}=F_{\text {in }}^{f}-\sum \rho_{\text {mol }}^{f} k_{\text {eff }}^{f s} S\left(y^{f s}-y_{\text {cat }}^{f s}\right)$ & Fuel flow rate change \\
\hline$k_{e f f}^{s}=D^{s} / C_{h}$ & Species effective mass transfer coefficient \\
\hline$D^{s}=D_{298}^{s} \varepsilon^{1.5}\left(\frac{T}{298}\right)^{1.5}$ & Species diffusivity \\
\hline$i^{A}=i_{0}^{A}\left[\exp \left(\frac{\alpha_{A}^{A} F\left(\eta^{A}-\eta_{e q}^{A}\right)}{R T}\right)-\exp \left(\frac{-\alpha_{C}^{A} F\left(\eta^{A}-\eta_{e q}^{A}\right)}{R T}\right)\right]$ & Anode local current density \\
\hline$i^{C}=i_{0}^{C}\left\lfloor\exp \left(\frac{\alpha_{A}^{C} F\left(\eta^{A}-\eta_{c q}^{A}\right)}{R T}\right)-\exp \left(\frac{-\alpha_{C}^{C} F\left(\eta^{A}-\eta_{c q}^{A}\right)}{R T}\right)\right\rfloor$ & Cathode local current density \\
\hline$i_{0}^{A}=i_{A}^{*}\left(y_{\text {cat }}^{H_{2}}\right)^{\gamma H_{2}}\left(y_{\text {cat }}^{H_{2} O}\right)^{\gamma H_{2} O} \exp \left(-\frac{E_{a c t}^{A}}{R T}\right)$ & Anode exchange current density \\
\hline
\end{tabular}

\section{Charge balance}

\begin{tabular}{ll}
\hline$C_{d L}^{A} \frac{d \eta_{A}}{d t}=\left(i_{\text {cell }}-i^{A}\right)$ & Charge balance anode/electrolyte interface \\
$C_{d L}^{C} \frac{d \eta_{C}}{d t}=\left(-i_{c e l l}-i^{C}\right)$ & Charge balance cathode/electrolyte interface
\end{tabular}

\section{Constitutive equations}




$$
\begin{aligned}
& i_{0}^{C}=i_{C}^{*}\left(y_{c a t}^{O_{2}}\right)^{\gamma O_{2}} \exp \left(-\frac{E_{a c t}^{C}}{R T}\right) \\
& i^{\text {cell }}=\left(E^{O C V}-E_{\text {cell }}-\eta_{\text {act }}^{A}+\eta_{\text {act }}^{C}\right) / R^{\text {Ohmic }} \\
& \eta_{\text {act }}^{A}=\eta^{A}-\eta_{e q}^{A} \\
& \eta_{a c t}^{C}=\eta^{C}-\eta_{e q}^{C} \\
& R^{\text {Ohmic }}=\delta_{e} / \sigma_{e} \\
& \sigma_{e}=3.34 \times 10^{4} \exp \left(-\frac{10300}{T}\right) \\
& r^{\mathrm{H}_{2} \mathrm{O}}=S \frac{v^{\mathrm{H}_{2} \mathrm{O}} i^{\mathrm{A}}}{n_{e}^{A} \mathrm{~F}} \\
& r^{O_{2}}=S \frac{v^{O_{2}} i^{C}}{n_{e}^{C} F} \\
& r^{H_{2}}=S \frac{v^{H_{2}} i^{A}}{n_{e}^{A} F} \\
& q^{f}=\alpha^{f} S\left(T^{P E N}-T^{f}\right) \\
& q^{a}=\alpha^{a} S\left(T^{P E N}-T^{a}\right) \\
& q^{P E N}=\left(-\frac{\Delta H_{R}}{2 F}-E_{\text {cell }}\right) I+\left(S \alpha^{f}+\frac{\left(C_{p}^{H_{2}}-C_{p}^{H_{2} O}\right)}{2 F} I\right)\left(T^{f}-T^{P E N}\right) \\
& +\left(S \alpha^{a}+\frac{C_{p}^{O_{2}}}{4 F} I\right)\left(T^{a}-T^{P E N}\right) \\
& U_{F}=1-\frac{y_{\text {out }}^{H_{2}} F_{\text {out }}^{A}}{y_{\text {in }}^{H_{2}} F_{\text {in }}^{A}} \\
& U_{A}=1-\frac{y_{\text {out }}^{O_{2}} F_{\text {out }}^{C}}{y_{\text {in }}^{O_{2}} F_{\text {in }}^{C}}
\end{aligned}
$$

Cathode exchange current density

Electrolyte current

Anode activation overpotential

Cathode activation overpotential

Electrolyte Ohmic resistance

Electrolyte conductivity

Water production rate

Oxygen consumption rate

Hydrogen consumption rate

Fuel channel heat transfer

Air channel heat transfer

PEN energy balance (net rate of energy accumulation)

Fuel utilisation

Air utilisation 
Table A2. Base case parameters and operating conditions of the planar SOFC compartment model.

\begin{tabular}{|c|c|c|}
\hline Parameter & Anode & Cathode \\
\hline Catalyst thickness $\delta, \mathrm{m}$ & $2.5 \times 10^{-4}$ & $3 \times 10^{-5}$ \\
\hline Porosity $\varepsilon$ & 0.4 & 0.4 \\
\hline Charge transfer coefficient $\alpha_{A}$ & 2 & 1.4 \\
\hline Charge transfer coefficient $\alpha_{C}$ & 1 & 0.6 \\
\hline Activation energy $E_{a c t}, \mathrm{~kJ} \mathrm{~mol}^{-1}$ & 120 & 130 \\
\hline Pre-exponential kinetics factor $i^{*}, \mathrm{~A} \mathrm{~m}^{-2}$ & $2.9 \times 10^{8}$ & $7.0 \times 10^{8}$ \\
\hline Heat transfer coefficient $\alpha, \mathrm{W} \mathrm{m}^{-2} \mathrm{~K}^{-1}$ & 25 & 25 \\
\hline Fluid physical properties & \multicolumn{2}{|c|}{ Calculated by Aspen Plus } \\
\hline Channel height $C_{h}, \mathrm{~m}$ & \multicolumn{2}{|c|}{$7.5 \times 10^{-4^{4}}$} \\
\hline Cell area $S, \mathrm{~m}^{2}$ & \multicolumn{2}{|c|}{$5 \times 10^{-3}$} \\
\hline Electrolyte thickness $\delta_{e}$, m & \multicolumn{2}{|c|}{$1 \times 10^{-5}$} \\
\hline PEN thermal capacity $\rho c_{p}{ }^{P E N}, \mathrm{~J} \mathrm{~m}^{-3} \mathrm{~K}^{-1}$ & \multicolumn{2}{|c|}{106} \\
\hline Species diffusivity at $298 \mathrm{~K} D_{298}^{s}, \mathrm{~m}^{2} \mathrm{~h}^{-1}$ & \multicolumn{2}{|c|}{$0.22\left(\mathrm{H}_{2}\right), 0.079\left(\mathrm{H}_{2} \mathrm{O}\right), 0.04\left(\mathrm{O}_{2}\right)$} \\
\hline $\begin{array}{l}\text { Stoichiometric coefficient } v \\
\text { Reaction rate exponent } \gamma\end{array}$ & \multicolumn{2}{|c|}{$\begin{array}{c}-1\left(\mathrm{H}_{2}\right), 1\left(\mathrm{H}_{2} \mathrm{O}\right),-0.5\left(\mathrm{O}_{2}\right) \\
1.0\left(\mathrm{H}_{2}\right), 1.0\left(\mathrm{H}_{2} \mathrm{O}\right), 0.25\left(\mathrm{O}_{2}\right)\end{array}$} \\
\hline \multicolumn{3}{|l|}{ Operating conditions } \\
\hline Cell voltage $E_{\text {cell }}, \mathrm{V}$ & \multirow{2}{*}{\multicolumn{2}{|c|}{$\begin{array}{c}0.80 \\
5.07 \times 10^{-5}\end{array}$}} \\
\hline Fuel flow rate $F_{i n}^{\dagger}, \mathrm{mol} \mathrm{s}^{-1}$ & & \\
\hline Air flow rate $F_{i n}^{a}, \mathrm{~mol} \mathrm{~s}^{-1}$ & \multicolumn{2}{|c|}{$6.17 \times 10^{-4}$} \\
\hline \multicolumn{3}{|l|}{ Fuel composition $y$, mole fraction } \\
\hline $\mathrm{H}_{2}$ & \multicolumn{2}{|c|}{0.97} \\
\hline $\mathrm{CH}_{4}$ & \multicolumn{2}{|c|}{0} \\
\hline $\mathrm{H}_{2} \mathrm{O}$ & \multicolumn{2}{|c|}{0.03} \\
\hline $\mathrm{C}_{2+}$ & \multicolumn{2}{|c|}{0} \\
\hline $\mathrm{CO}$ & \multicolumn{2}{|c|}{0} \\
\hline $\mathrm{CO}_{2}$ & \multicolumn{2}{|c|}{0} \\
\hline Fuel inlet temperature, $\mathrm{K}$ & \multicolumn{2}{|c|}{1073} \\
\hline Air inlet temperature, $\mathrm{K}$ & \multicolumn{2}{|c|}{1073} \\
\hline Stream and SOFC pressure, atm & \multicolumn{2}{|c|}{1} \\
\hline
\end{tabular}




\section{Appendix B}

The number of compartments, $n$, and their configuration needed to approximate a particular reactor of interest can be estimated from its residence time distribution (RTD). Krewer et al. (2004) reported an experimentally measured RTD for a fuel cell reactor. These data were used to estimate a typical $n$ value for the channel scale modelling work. The response of $n$ ideal, well mixed reactors in series to a step change in inlet tracer concentration (Levenspiel, 1999) is:

$$
F=1-e^{-n \theta} \sum_{i=1}^{n} \frac{(n \theta)^{i-1}}{(i-1) !}
$$

where $F$ is the dimensionless tracer concentration exiting the last reactor and $\theta$ is the dimensionless time. The $n$ value that yields the best fit to experimental data will be used as a reasonable $n$ in this study.

Figure B1 shows the responses of different numbers of reactors in series compared to the experimental data of Krewer et al. (2004). It can be seen that for these data, $n=4-6$ provides an adequate fit. In the current study, we consequently selected $n=6$ as a reasonable typical value to proceed with further modelling. 
Figure 1. Multi-scale modelling framework and software interactions for SOFC simulation: undertaken (compartment, channel and cell scales) and planned (stack and system scales).

Figure 2. Compartment scale response of cell temperature to stepwise changes in the air flow rate.

Figure 3. Compartment scale response of cell temperature to stepwise changes in the fuel flow rate.

Figure 4. Channel scale fuel utilization trends for different flow patterns: (A) fuel utilization profiles for cross-current flow (solid surface) and counter-current flow (mesh surface); (B) fuel utilization profiles for cross-current flow (solid surface) and co-current flow (mesh surface); (C) ratio of fuel utilization in cross-current flow to that in counter-current flow; and (D) ratio of fuel utilization in cross-current flow to that in co-current flow.

Figure 5. Effect of fuel flow rate on current distribution profile in a channel for various flow patterns.

Figure 6. Ratio of current distribution in a channel in the cross-current configuration to that in counter-current configuration for different fuel rates.

Figure 7. Effect of fuel flow rate on temperature distribution profile in a channel for various flow patterns.

Figure 8. 2D Aspen Plus representation of a cross-current SOFC for the sensitivity analysis and optimisation of the air distribution at the cell scale. Equal fuel flows are provided by flow splitter $B 2$. Optimisation is performed on the air flow distribution in flow splitter $B 1$.

Figure 9. Effect of fuel flow rate on key distributed variables in a $2 \mathrm{D}$ cell for constant air flow rate conditions: (A) fuel flow rate 10\% lower than base case, (B) base case fuel flow rate, and (C) fuel flow rate $10 \%$ higher than base case.

Figure 10. Effect of air flow rate on key distributed variables in a 2D cell for constant fuel flow rate conditions: (A) air flow rate $20 \%$ lower than base case, (B) base case air flow rate, and (C) air flow rate $20 \%$ higher than base case.

Figure 11. PEN temperature and other distributed variables in a $2 \mathrm{D}$ cell for non-optimised (A) and optimised (B) air flow distributions.

Figure 12. Effect of fuel flow rates on the optimum air flow profile for constant total air flow rate.

Figure B1. Comparison of the RTD of $n$ well mixed reactors in series with the experimental fuel cell data of Krewer et al. (2004) for the purposes of establishing typical $n$. 
Highlights

- This study developed a non-isothermal, spatially distributed model for a SOFC channel and cell.

- The model can capture any fuel-air flow pattern within a flowsheeting environment.

- Sensitivity analysis and thermal optimisation are carried out by using the process analysis facilities within Aspen Plus.

- An optimum air distribution profile was determined for a cell of a SOFC that minimises the temperature gradient. 
Compartment Scale $(1 \mu \mathrm{m}-1 \mathrm{~cm})$ Typical Issues

- Reaction kinetics, heat and mass transfer

- Fuel conversion, carbon deposition

- Catalyst and material improvements

\begin{tabular}{|c|c|c|}
\hline \multirow{2}{*}{$\begin{array}{l}\text { Anode } \\
\text { Inlet }\end{array}$} & \multirow{2}{*}{$\begin{array}{l}\text { Anode channel } \\
\text { well mixed flow }\end{array}$} & \multirow{2}{*}{$\begin{array}{l}\text { Anode } \\
\text { Outlet }\end{array}$} \\
\hline & & \\
\hline \multirow{2}{*}{$\begin{array}{l}\text { Cathode } \\
\text { Inlet }\end{array}$} & Solid electrolyte & \multirow{2}{*}{$\begin{array}{c}\text { Cathode } \\
\text { Outlet }\end{array}$} \\
\hline & Cathode channel & \\
\hline
\end{tabular}

\section{Channel Scale $(1 \mathrm{~cm}-10 \mathrm{~cm})$}

\section{Typical Issues}

- Fuel and air flow configuration

- Fluid flow regimes

- Residence time distributions

Fresh Fuel

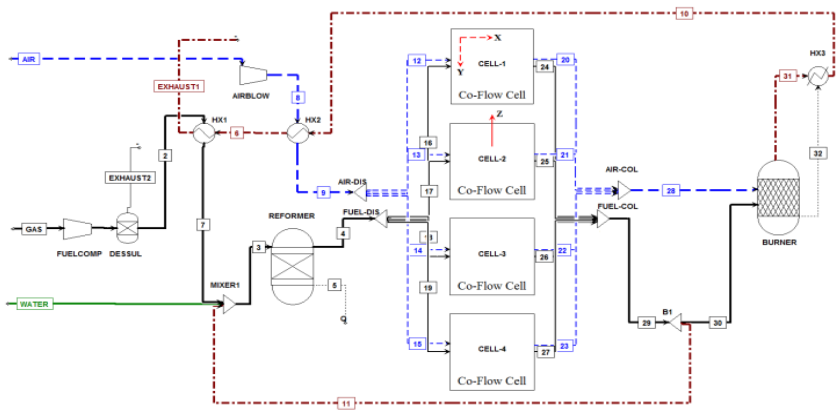

System Scale $(1 \mathrm{~m}-10 \mathrm{~m})$

Typical Issues

- Process optimisation

- Process dynamics and contro

- Process commercialisation

\section{Modelling communication framework}
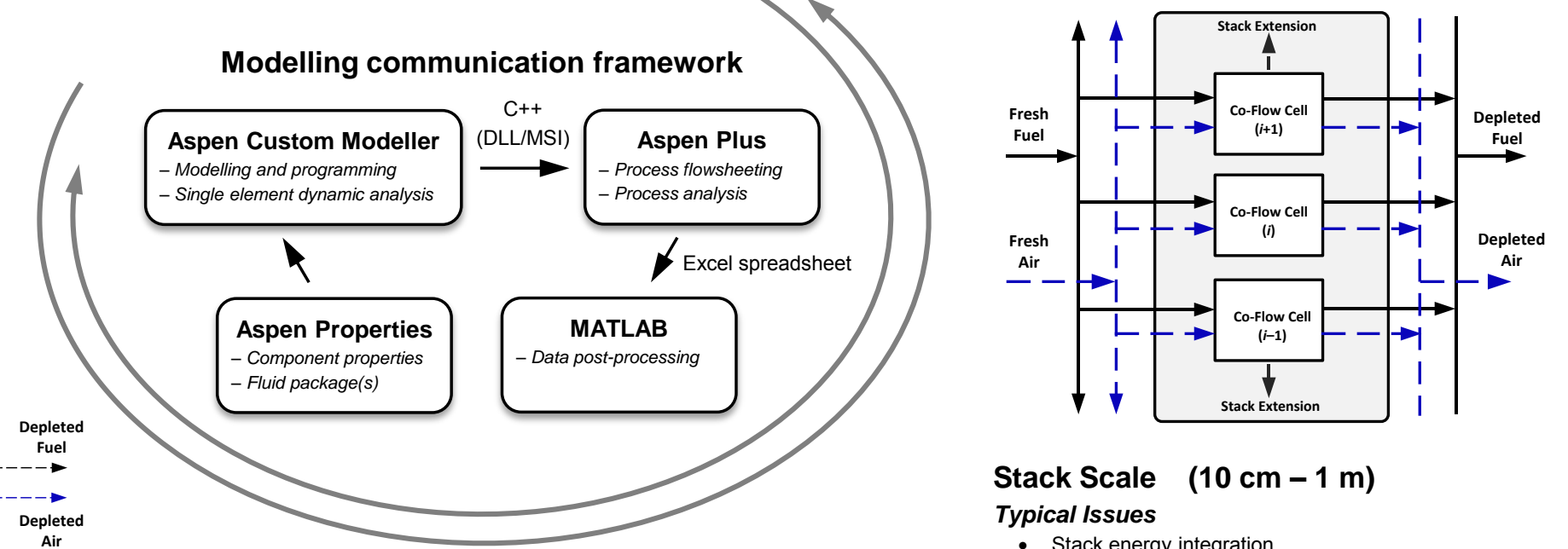

\section{Stack Scale $\quad(10 \mathrm{~cm}-1 \mathrm{~m})$}

Typical Issues

- Stack energy integratio

- Process steadiness

- Start-up and shut-down dynamics

Cell Scale $(1 \mathrm{~cm}-10 \mathrm{~cm})$ Typical Issues

- Thermal management

- Cell life durability

- Dynamic cell behaviour

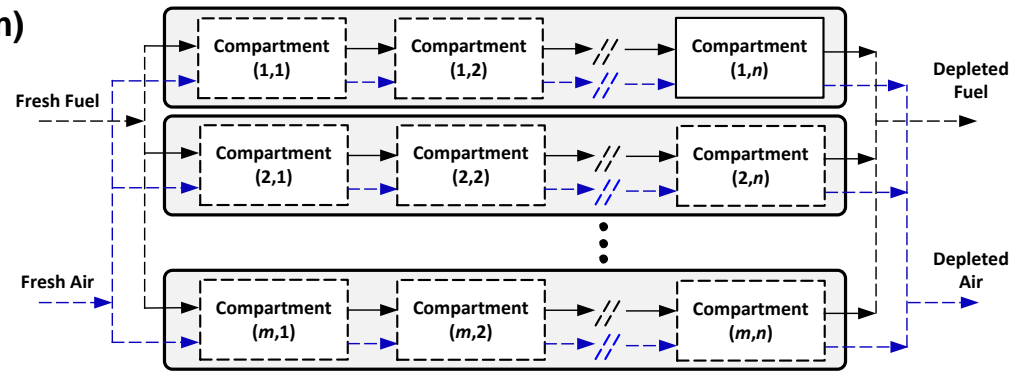


Compartment Scale $(1 \mu \mathrm{m}-1 \mathrm{~cm})$ Typical Issues

- Reaction kinetics, heat and mass transfer

- Fuel conversion, carbon deposition

- Catalyst and material improvements

\begin{tabular}{|c|c|c|}
\hline \multirow{2}{*}{$\begin{array}{l}\text { Anode } \\
\text { Inlet }\end{array}$} & \multirow[b]{2}{*}{$\begin{array}{l}\text { Anode channel } \\
\text { well mixed flow }\end{array}$} & \\
\hline & & Outlet \\
\hline \multirow{2}{*}{$\begin{array}{l}\text { Cathode } \\
\text { Inlet }\end{array}$} & Solid electrolyte & \multirow{2}{*}{$\begin{array}{c}\text { Cathode } \\
\text { Outlet }\end{array}$} \\
\hline & $\begin{array}{l}\text { Cathode channel } \\
\text { well mixed flow }\end{array}$ & \\
\hline
\end{tabular}

\section{Channel Scale $(1 \mathrm{~cm}-10 \mathrm{~cm})$}

\section{Typical Issues}

- Fuel and air flow configuration

- Fluid flow regimes

- Residence time distributions

Fresh Fuel

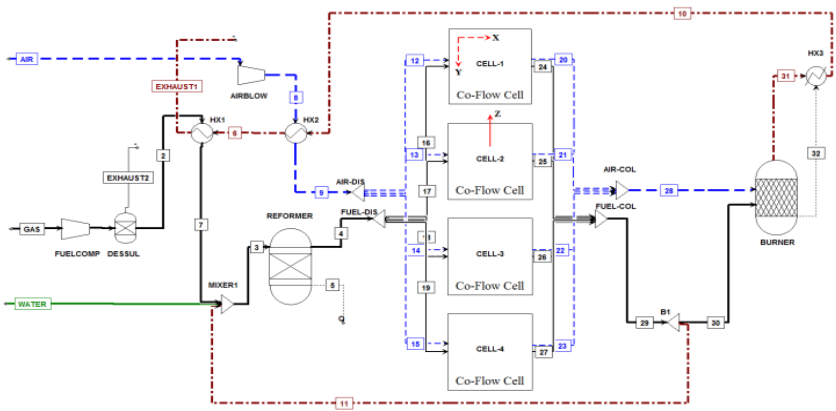

System Scale $(1 \mathrm{~m}-10 \mathrm{~m})$

Typical Issues

- Process optimisation

- Process dynamics and contro

- Process commercialisation

\section{Modelling communication framework}
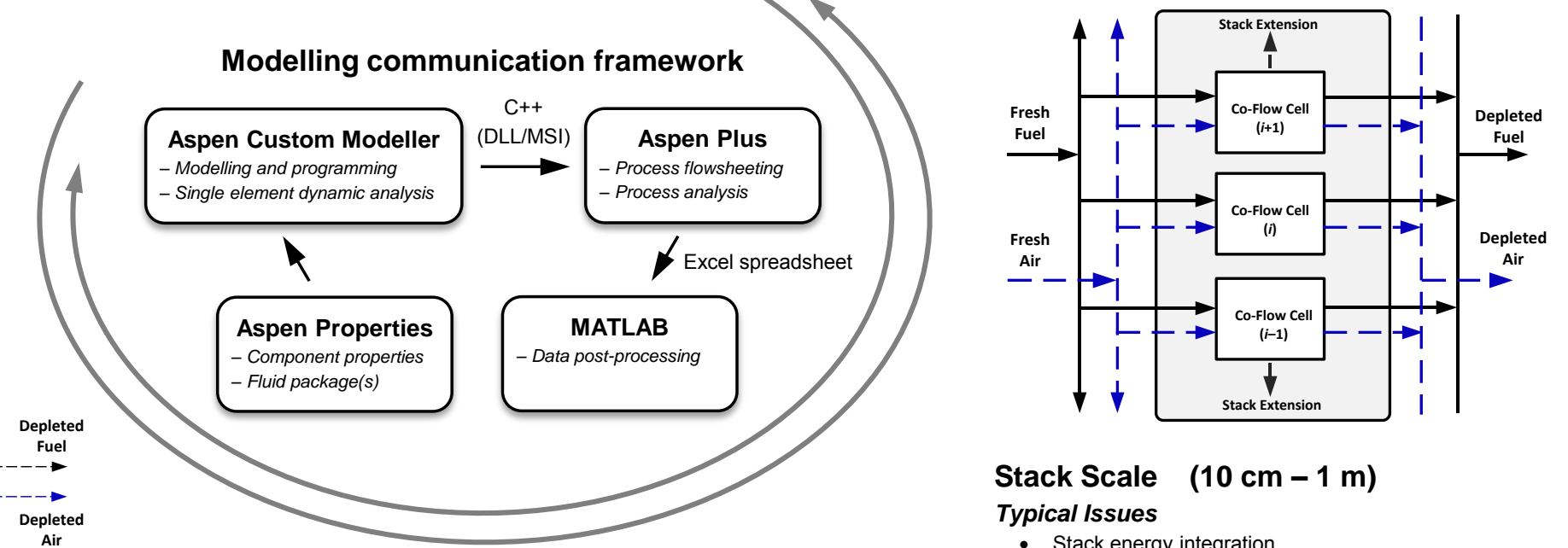

\section{Stack Scale $\quad(10 \mathrm{~cm}-1 \mathrm{~m})$}

Typical Issues

- Stack energy integratio

- Process steadiness

- Start-up and shut-down dynamics

Cell Scale $(1 \mathrm{~cm}-10 \mathrm{~cm})$ Typical Issues

- Thermal management

- Cell life durability

- Dynamic cell behaviour

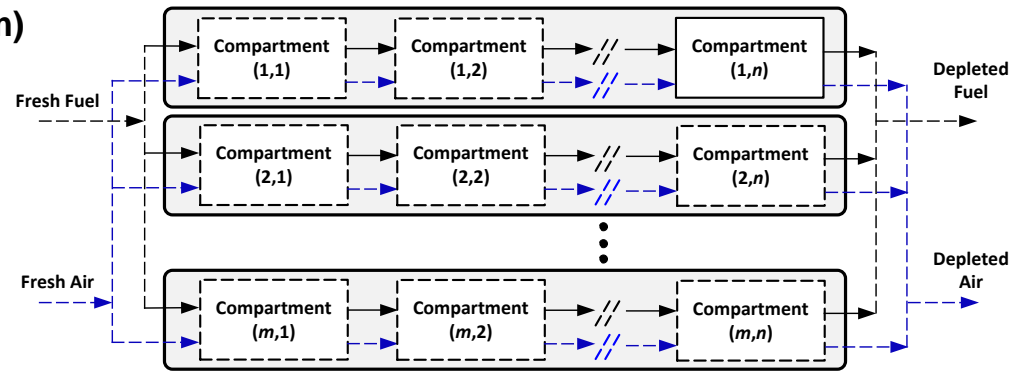




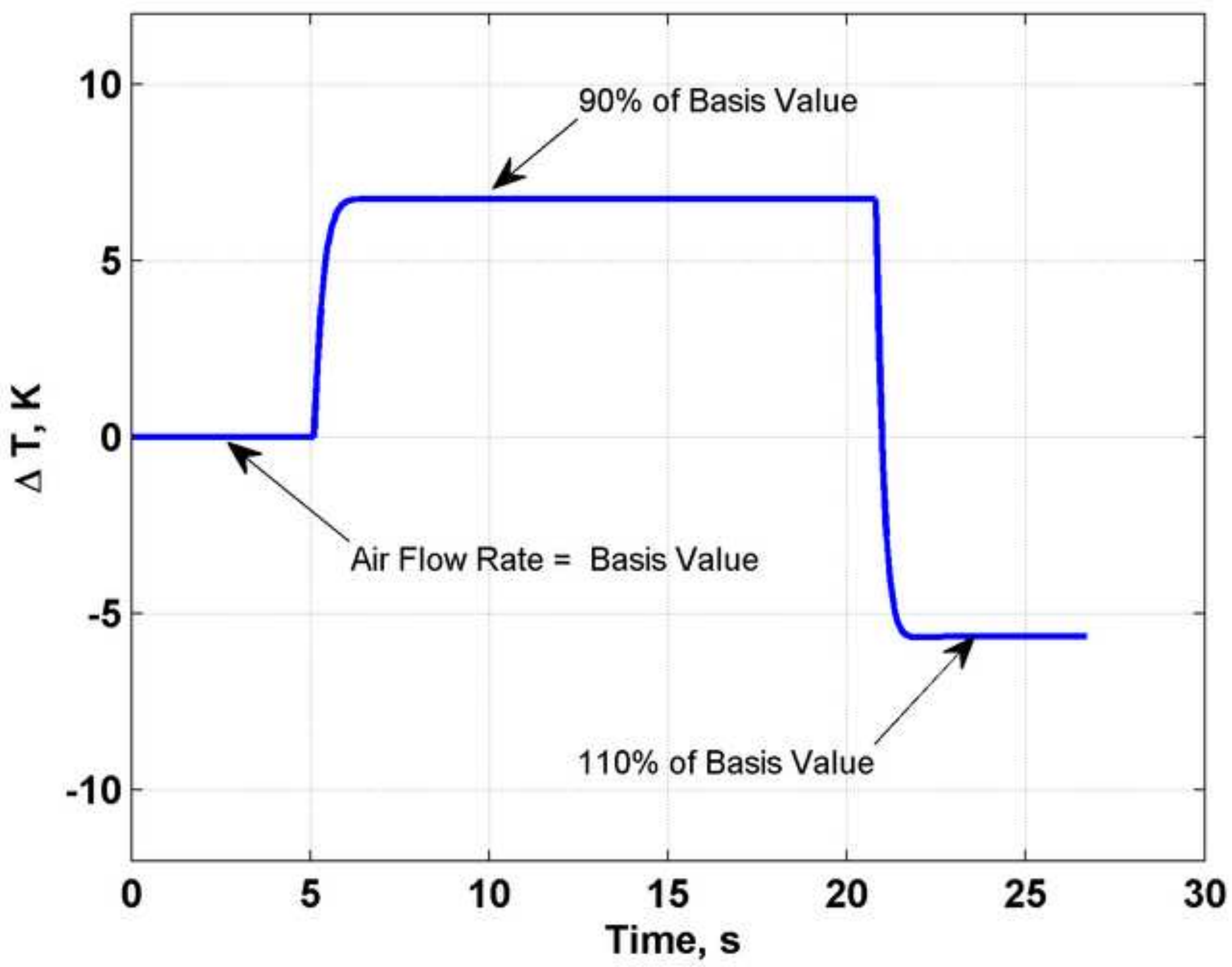




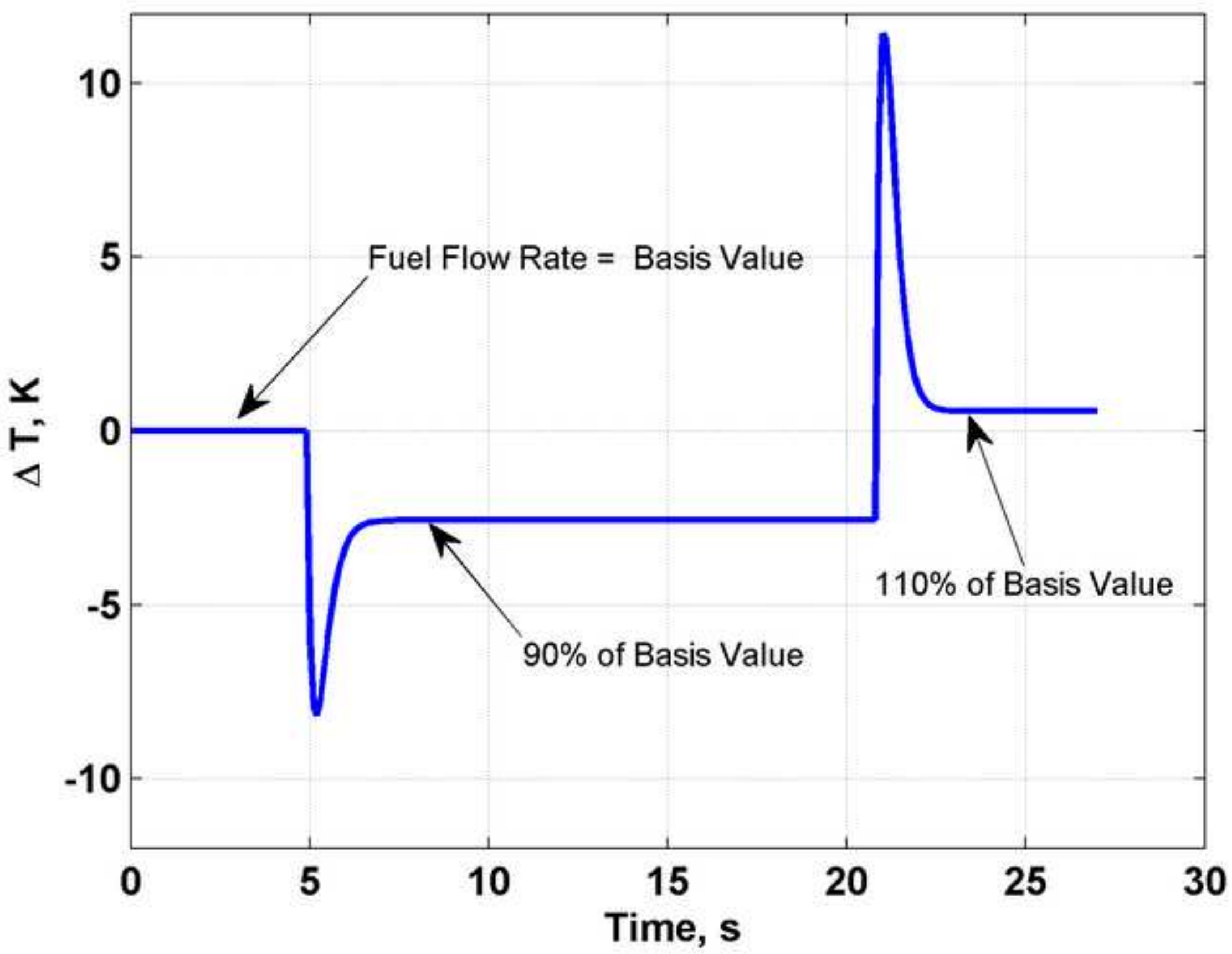


Click here to download high resolution image
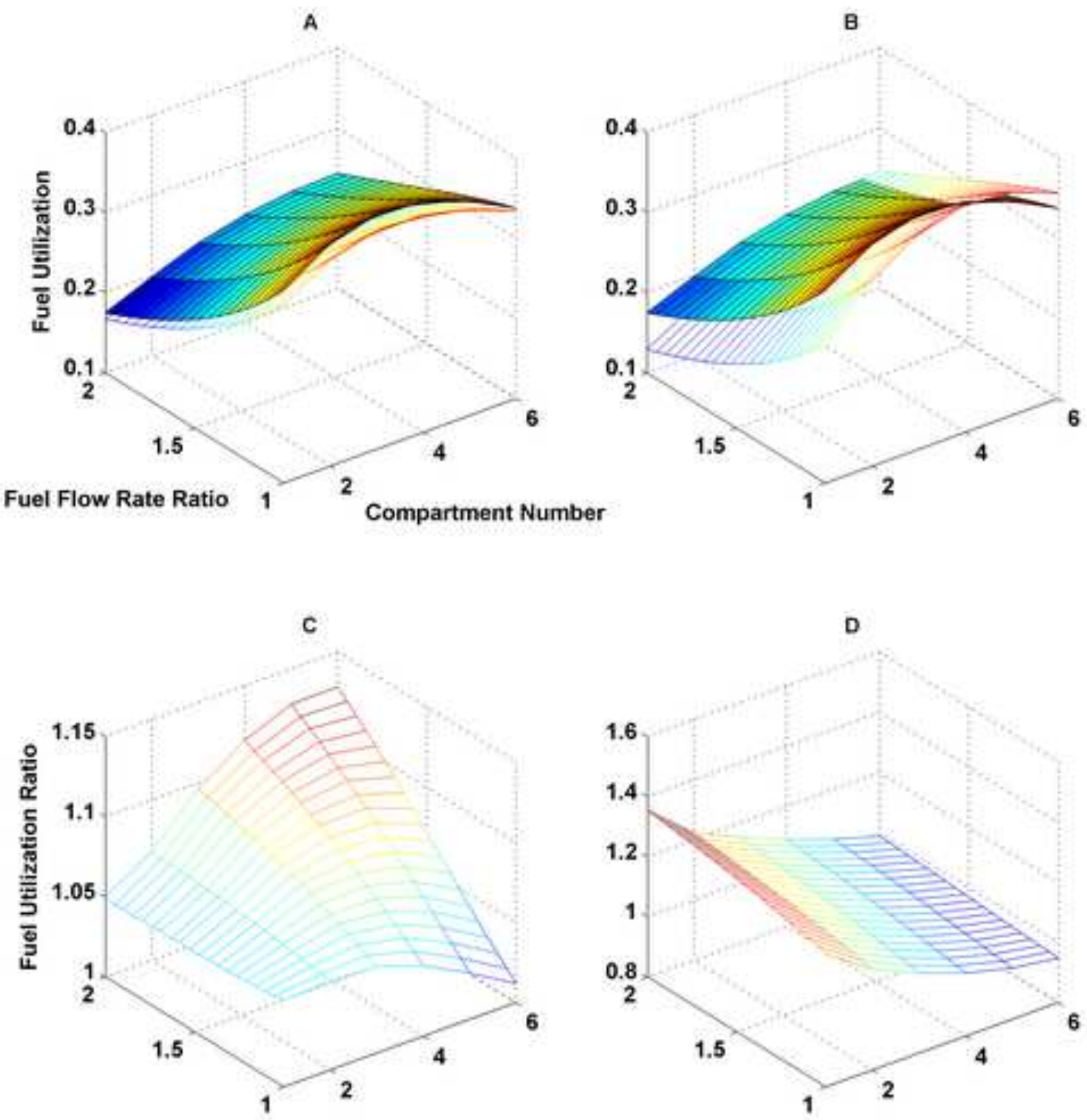
Click here to download high resolution image
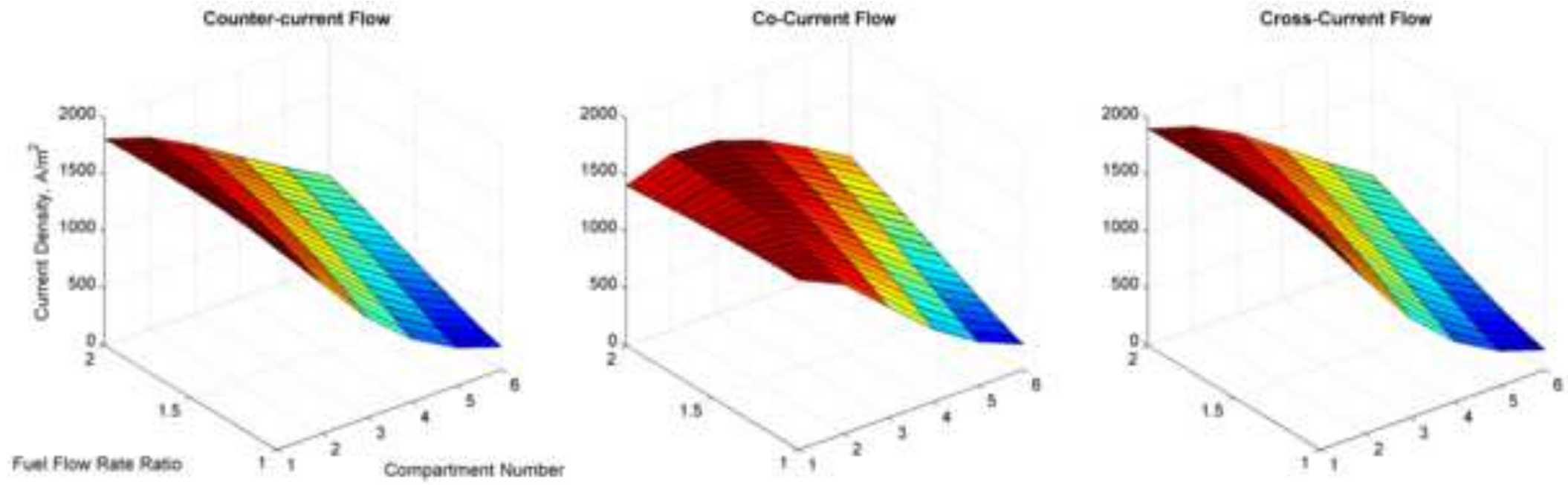


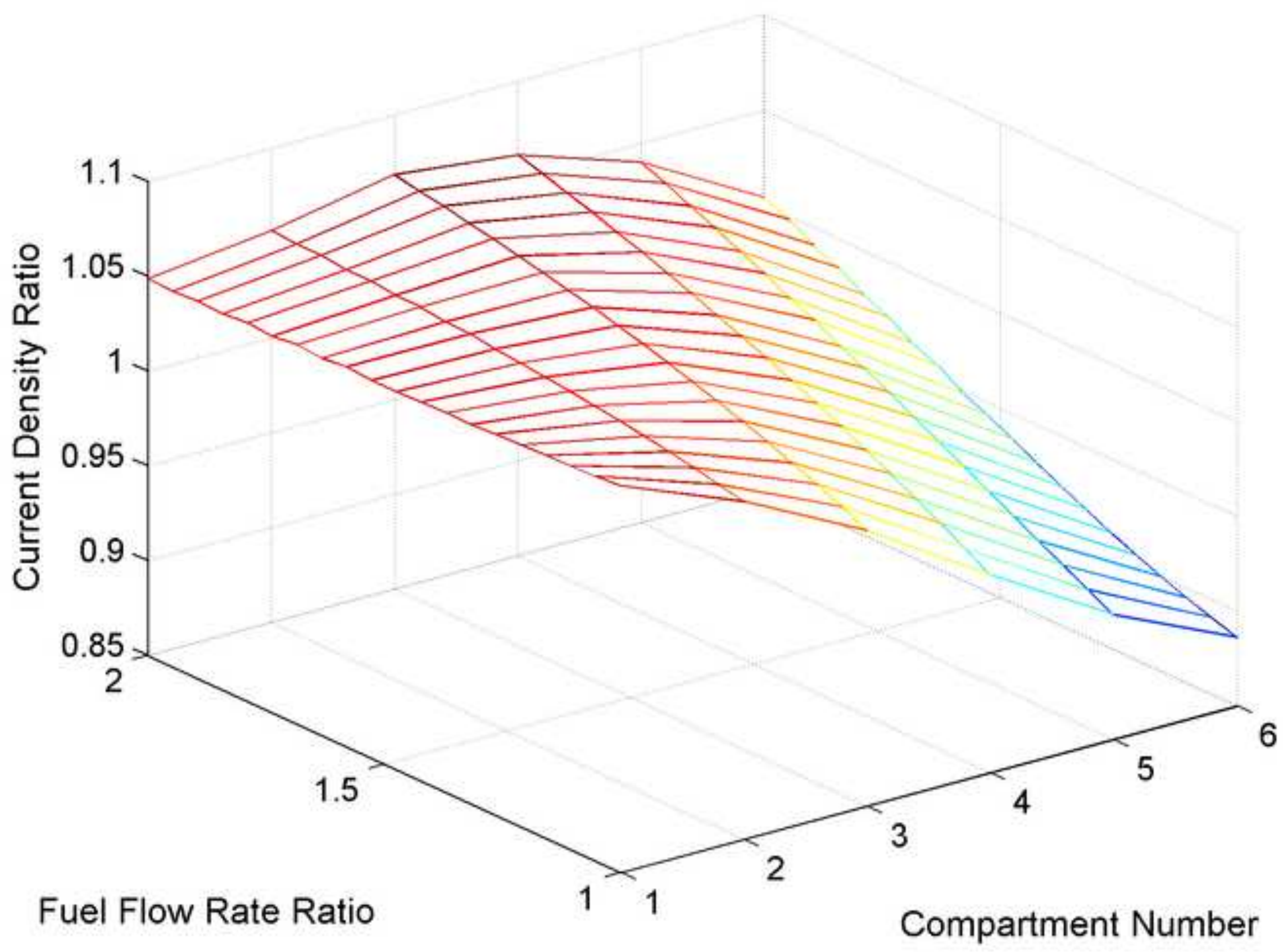


Click here to download high resolution image
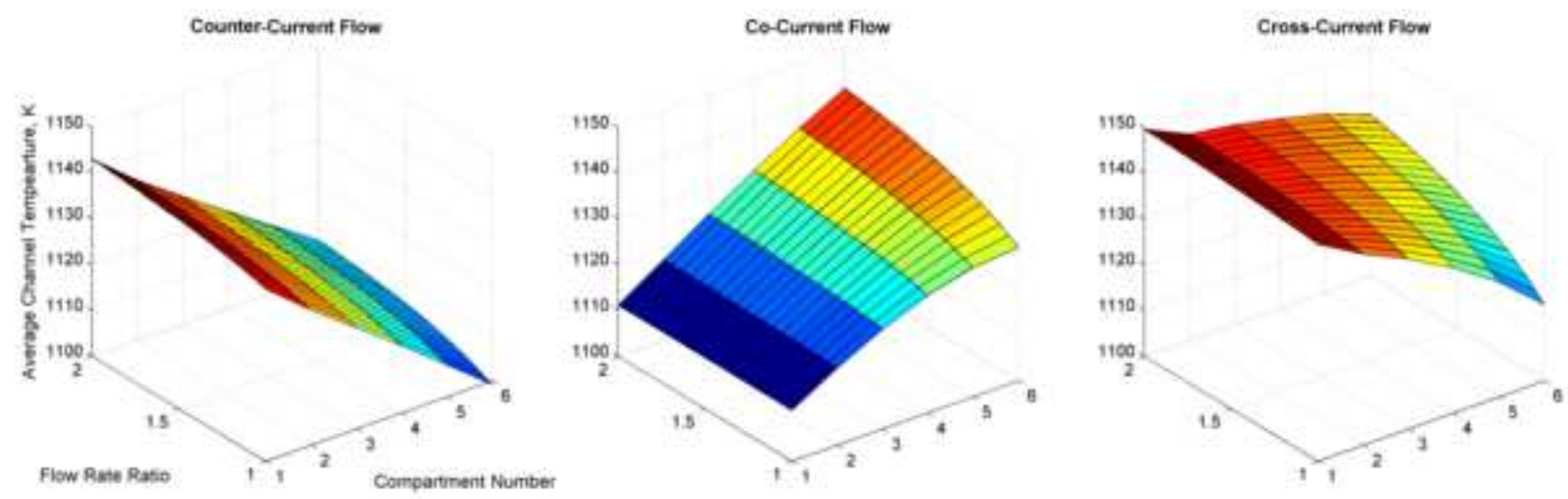
A

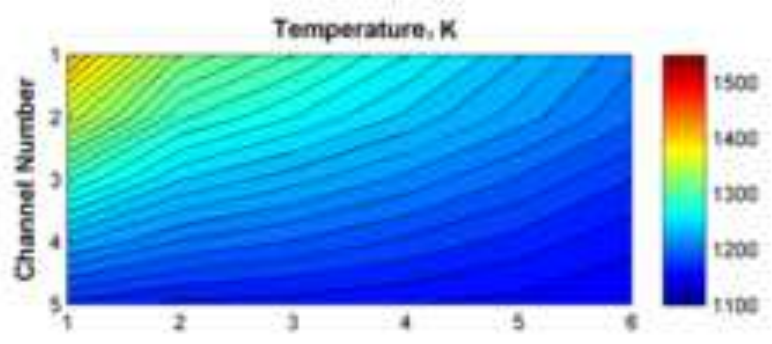

Current Density, A/m ${ }^{2}$

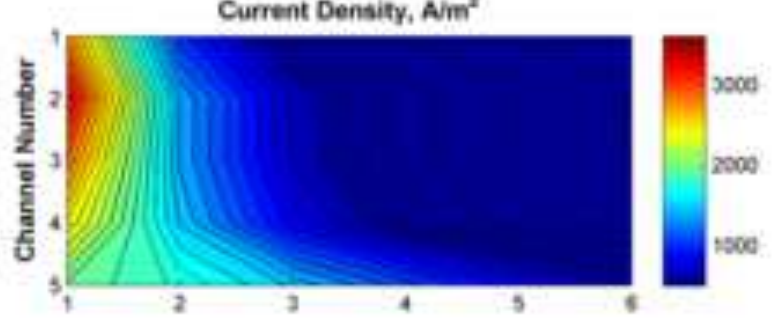

Hydrogen Wole Fraction

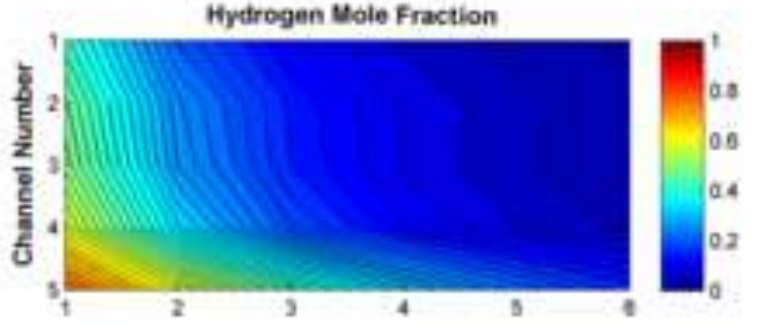

Nernst Voltage, $V$

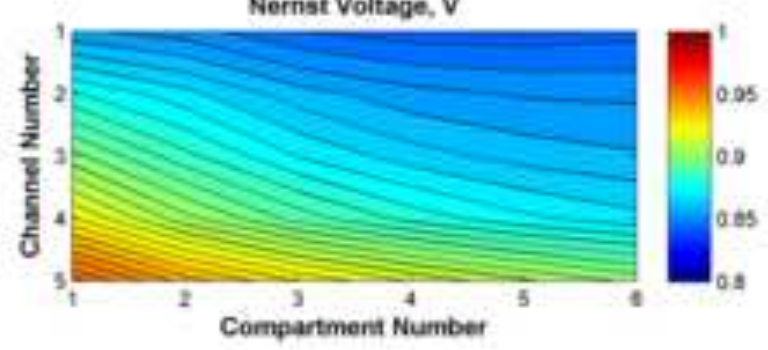

B

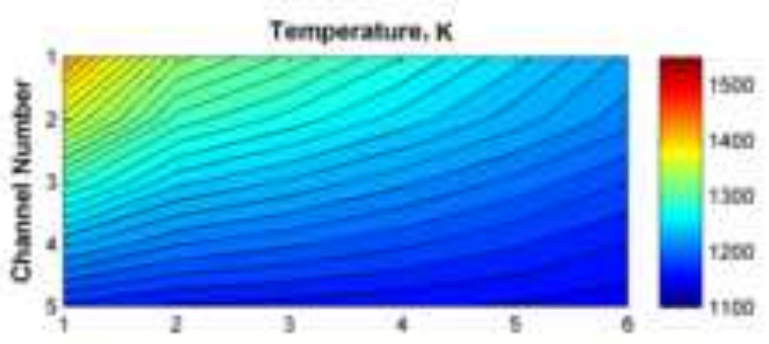

Current Density, A/m²

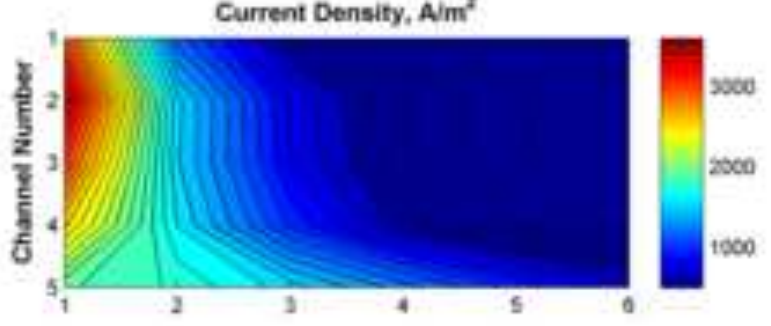

Hydrogen Mole Fraction

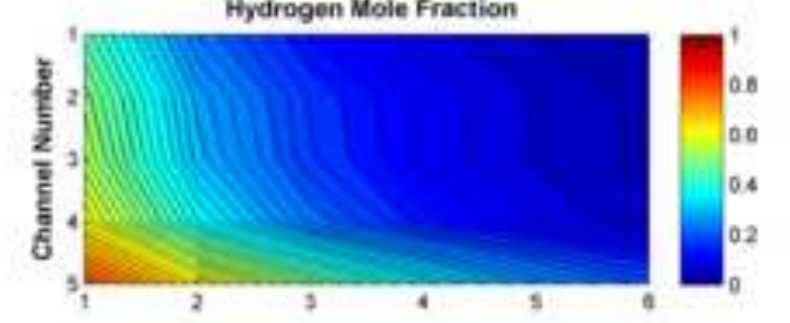

Nomat Voltage, $\mathrm{V}$

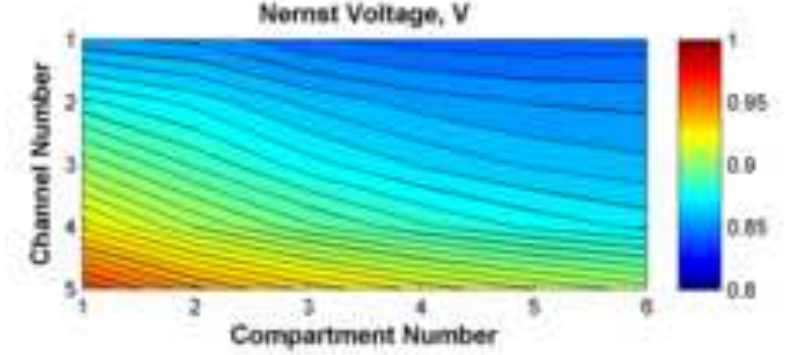

C
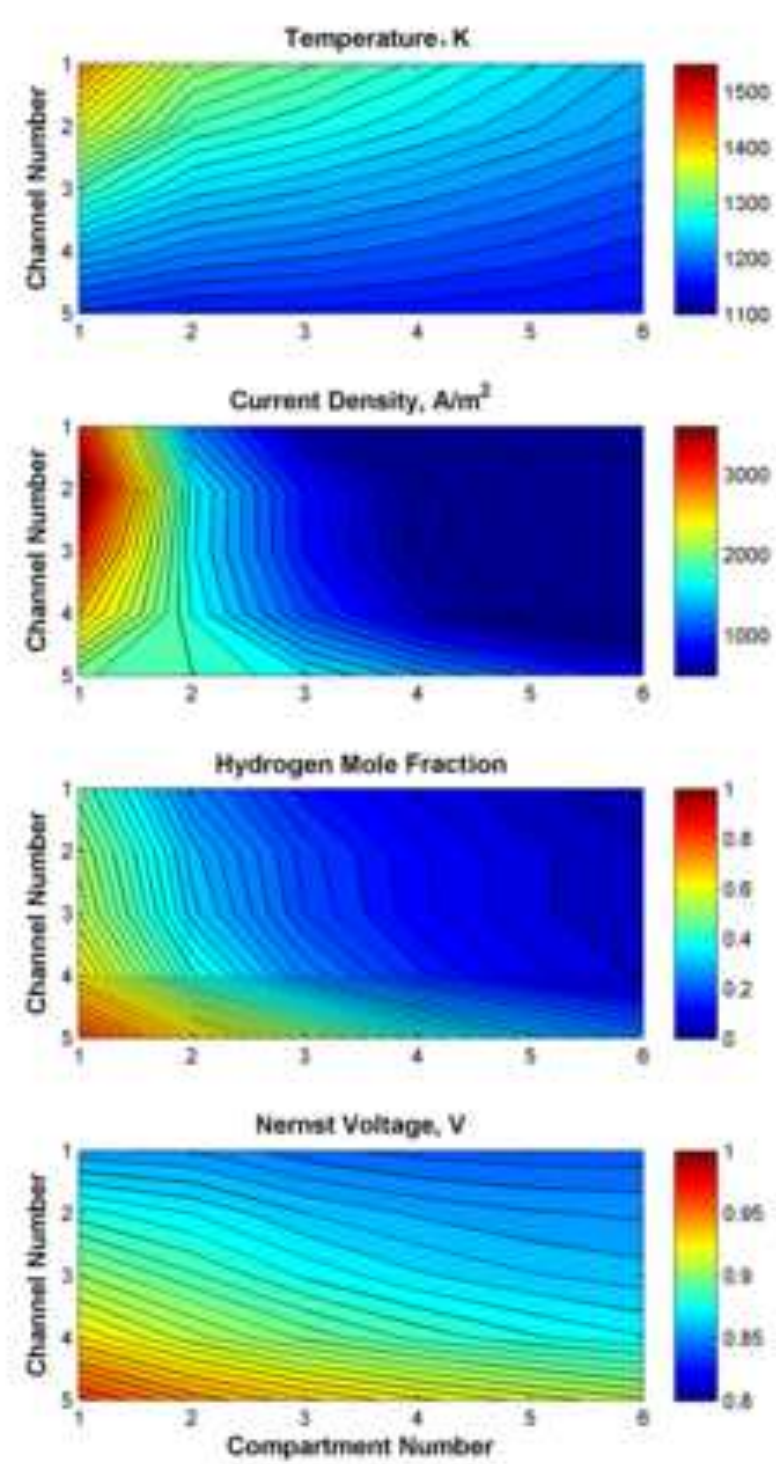
Click here to download high resolution image

A

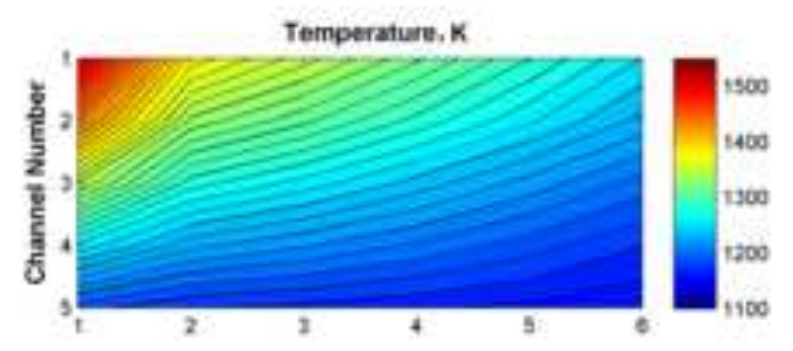

Current Density, A/m²

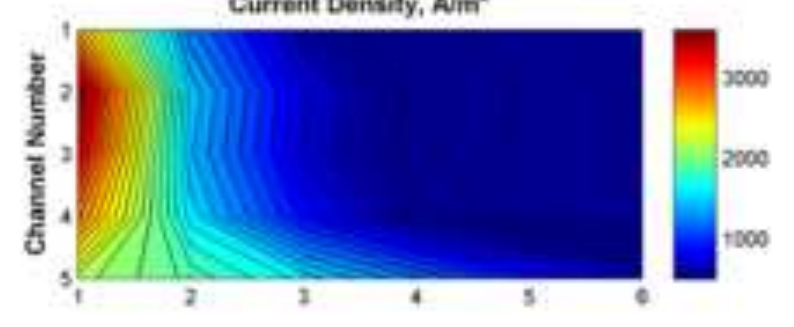

Hydrogen Mole Fraction
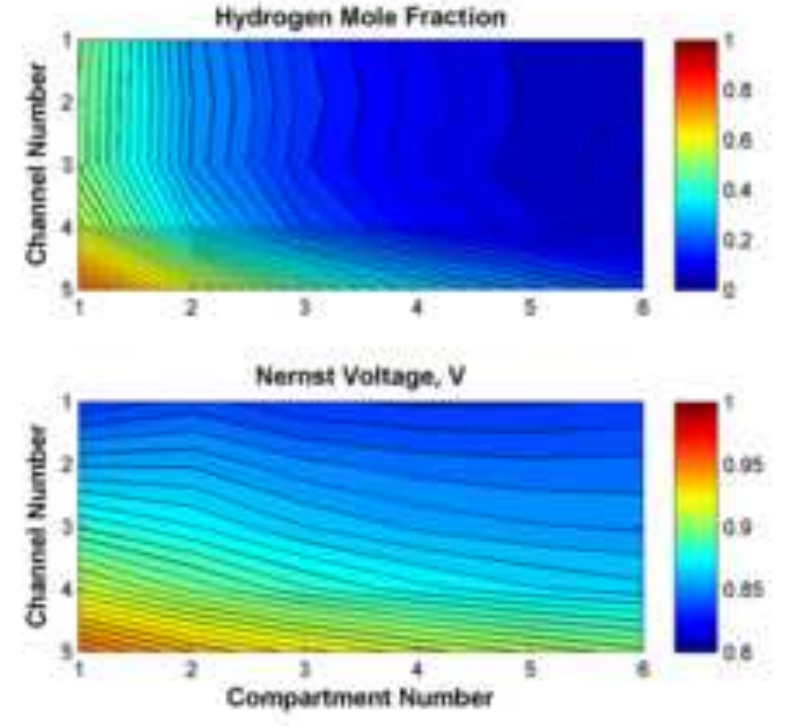

B

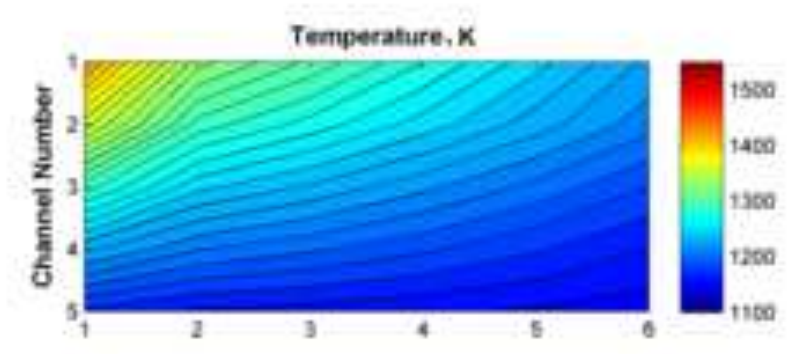

Current Density, A/m²

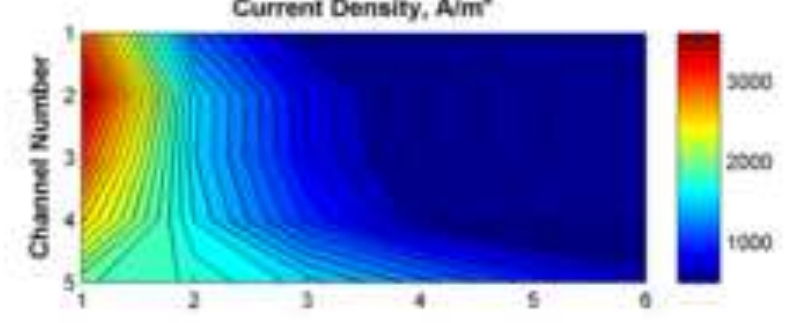

Hydrogen Mole Fraction

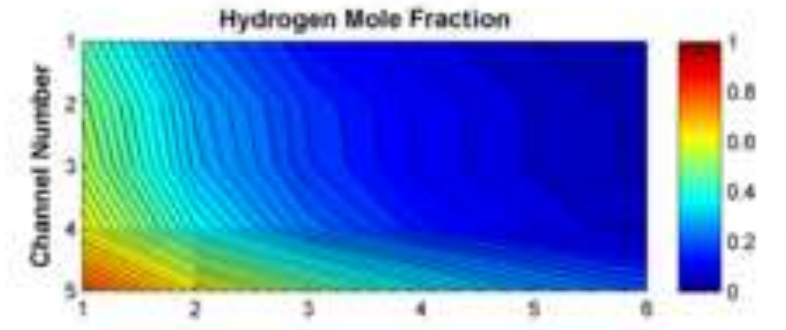

Nomat Voltage, $\mathrm{V}$

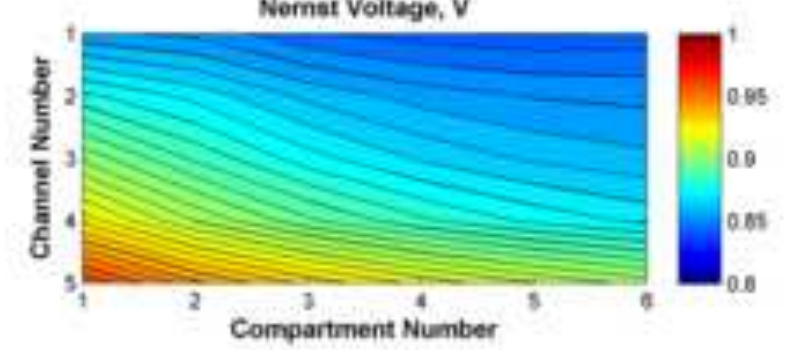

C
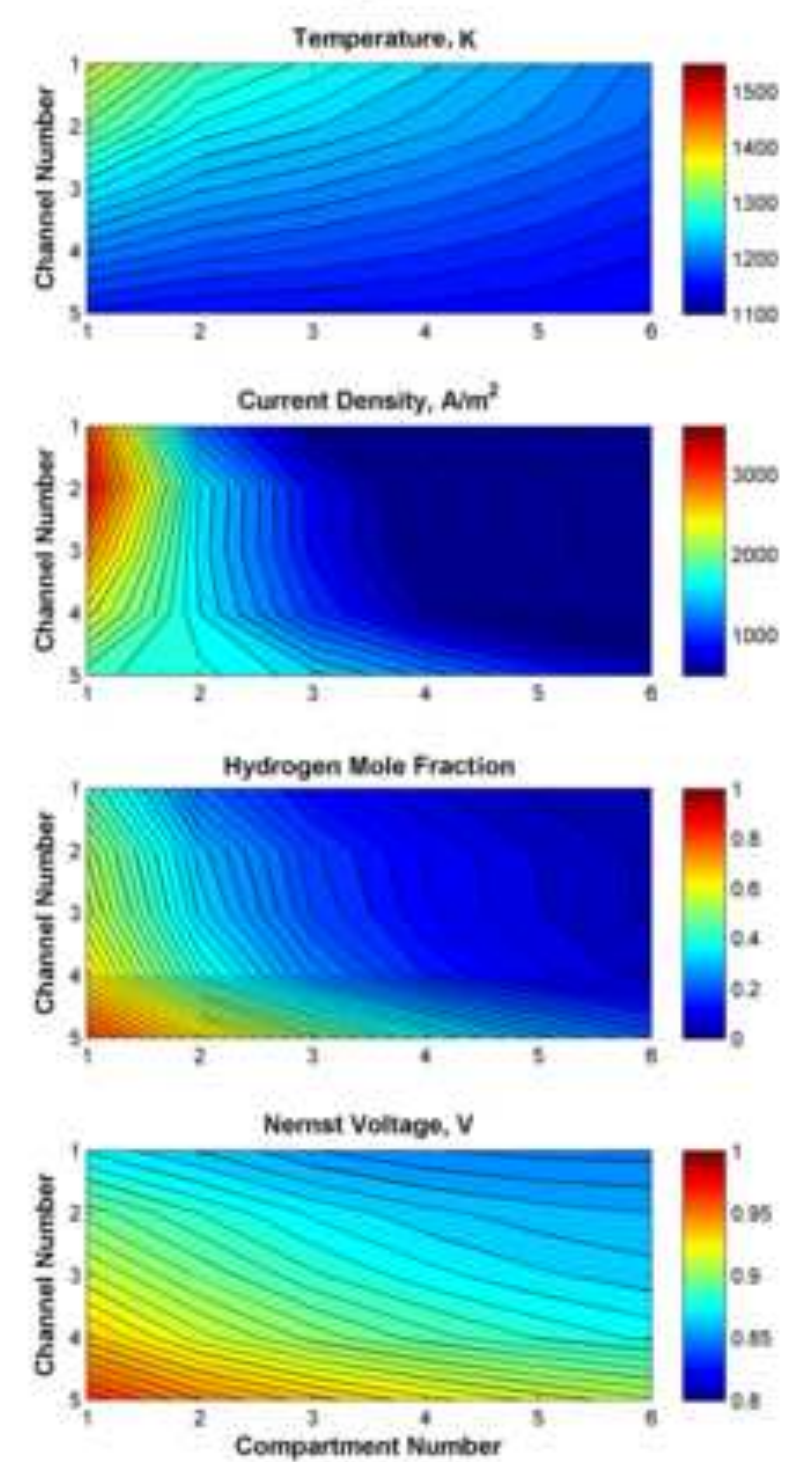
Click here to download high resolution image

A

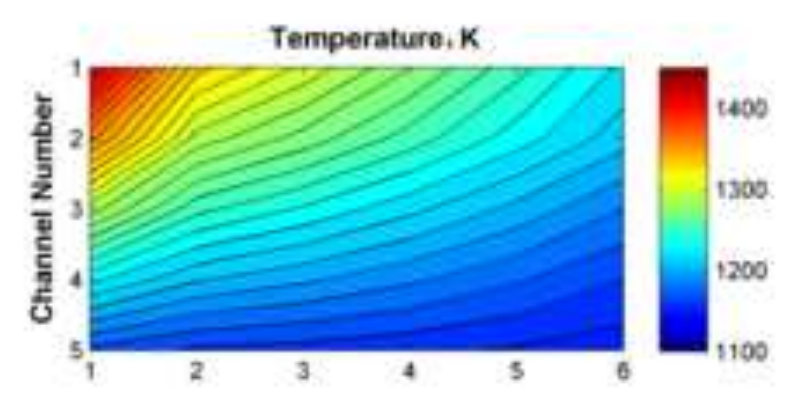

Current Density, $\mathrm{Alm}^{2}$

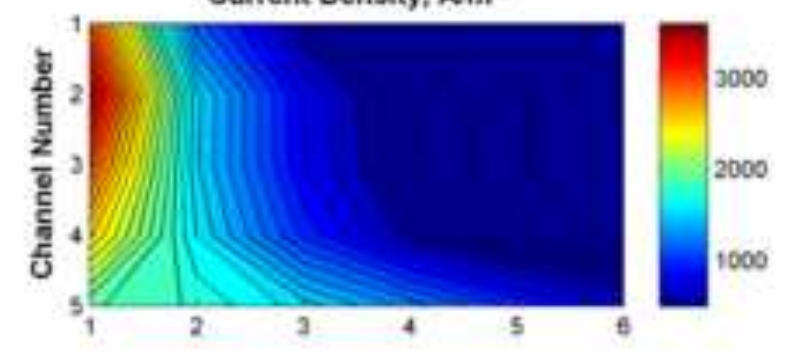

Hydrogen Mole Fraction
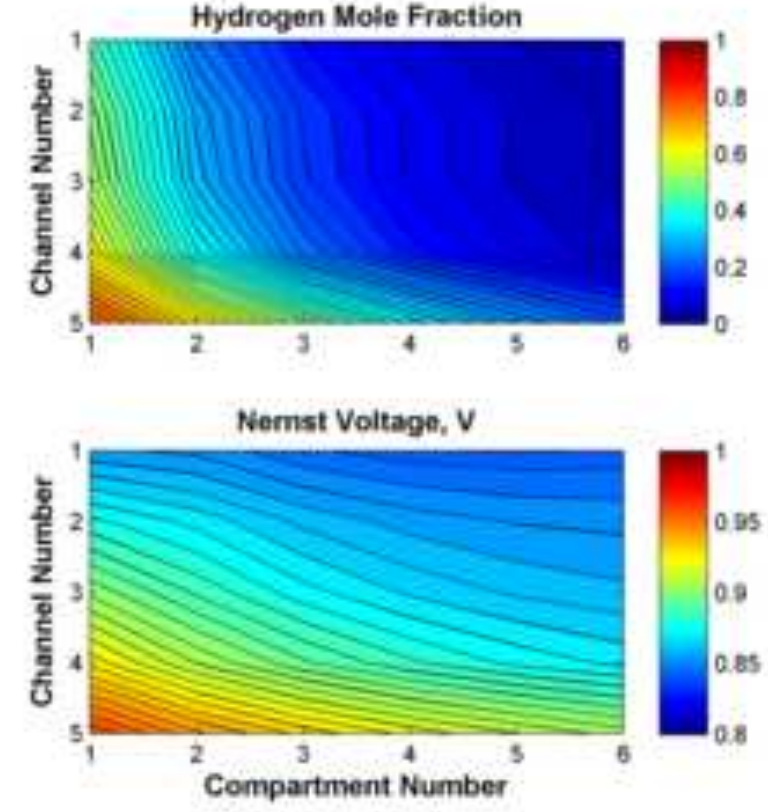

B

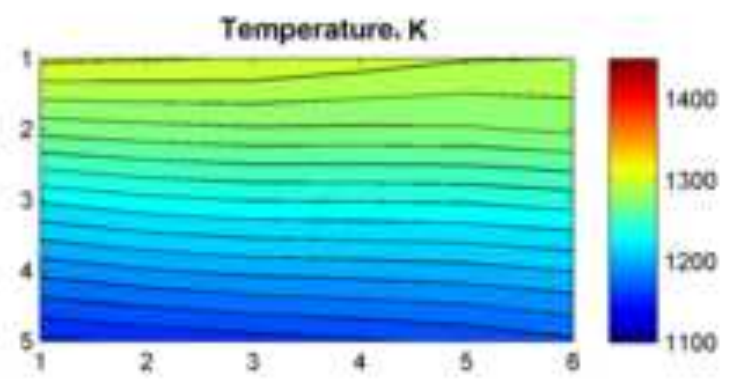

Current Density, $\mathrm{Am}^{2}$

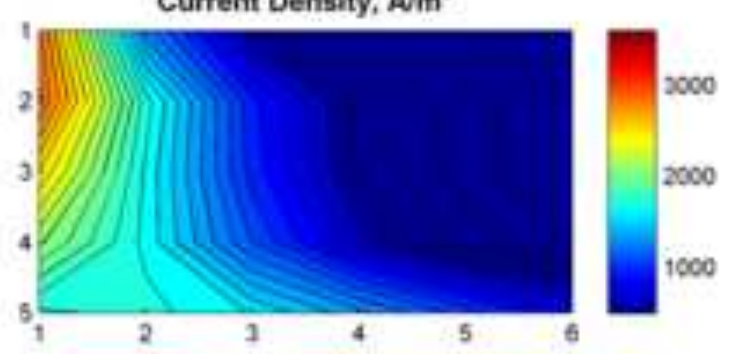

Hydrogen Mole Fraction

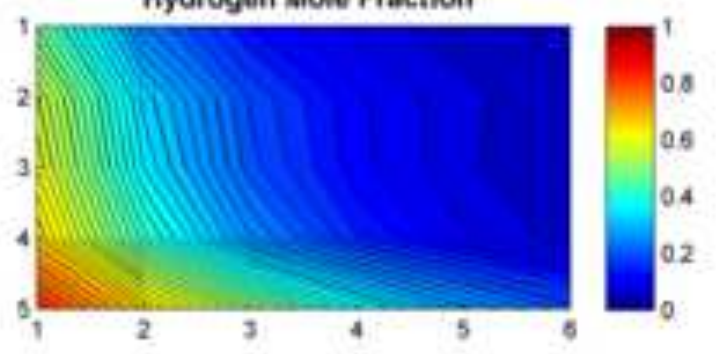

Nernst Voltage, $v$

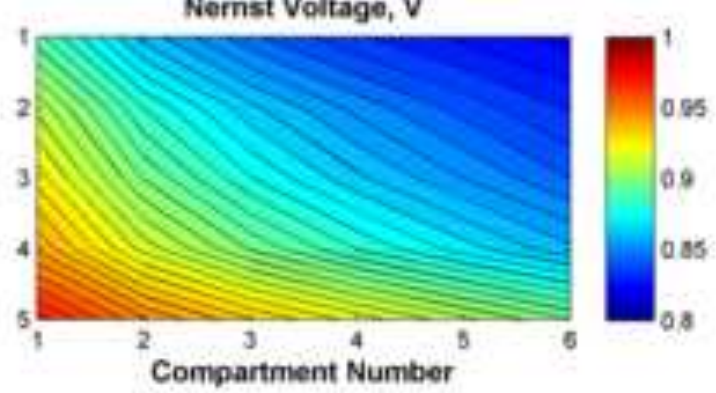


Figure(12)

Click here to download high resolution image

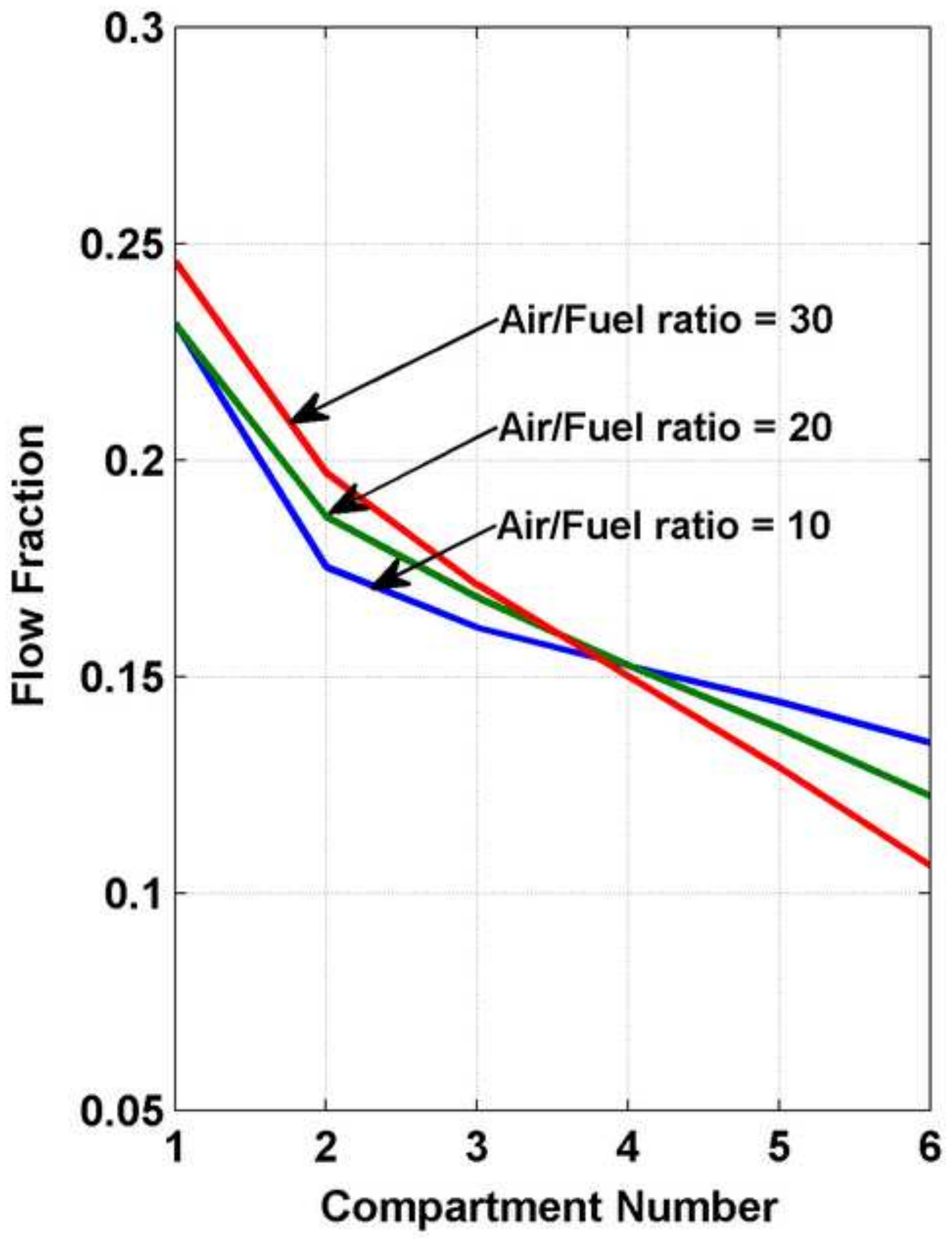


Figure(B1)

Click here to download high resolution image

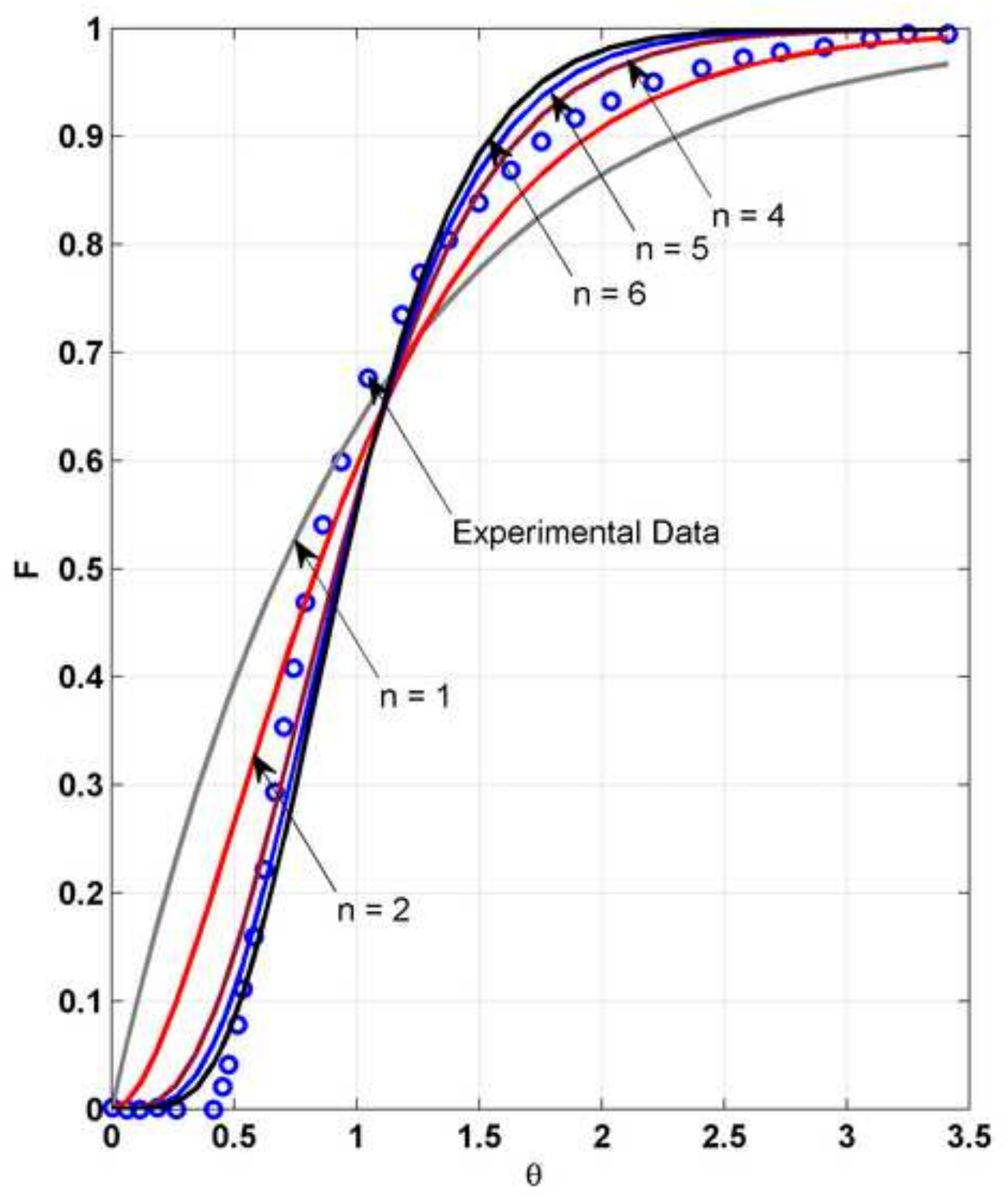

